\title{
Deflection and Vibration Control of Laminated Plates Using Extension and Shear Actuated Fiber Composites
}

\author{
S. Raja, ${ }^{1}$ Tadashige Ikeda, ${ }^{2}$ and D. Dwarakanathan ${ }^{1}$ \\ ${ }^{1}$ National Aerospace Laboratories, CSIR, Bangalore 560017, India \\ ${ }^{2}$ Department of Aerospace Engineering, Nagoya University, Nagoya 4648603, Japan
}

Correspondence should be addressed to S. Raja, raja@nal.res.in

Received 10 October 2010; Revised 16 February 2011; Accepted 16 February 2011

Academic Editor: Marcelo A. Trindade

Copyright ( 92011 S. Raja et al. This is an open access article distributed under the Creative Commons Attribution License, which permits unrestricted use, distribution, and reproduction in any medium, provided the original work is properly cited.

\begin{abstract}
The use of surface bonded and embedded piezoelectric composite actuators is examined through a numerical study. Modelling schemes are therefore developed by applying the isoparametric finite element approach to idealise extension-bending and shearbending couplings due to piezoelectric actuations. A modal control based linear quadratic regulator is employed to perform the active vibration control studies. Influence of shear actuation direction and its width has been examined and interesting deflection patterns are noticed. The through width SAFC develops a constant deflection beyond its length along the laminated plate length. In contrast, segmented SAFC produces a moderate to linearly varying deflection pattern. MFC actuators have shown promising features in vibration control performances. Nevertheless, closed loop damping presents the efficiency of SAFC in the vibration control application. It is therefore envisaged that optimally actuated smart laminates can be designed using MFC and SAFC to efficiently counteract the disturbance forces.
\end{abstract}

\section{Introduction}

The piezoelectric composite actuators, namely, active fiber composite (AFC) and macrofiber composite (MFC), are presently considered for structural control and health monitoring applications due to their improved performances over monolithic parental crystals. Hagood and Bent [1], Bent [2], and Wilkie et al. [3] were the researchers, who had developed the fiber-based active device concepts, employing the sophisticated interdigitated electrodes [1-3]. These actuators are now commercially available in two actuation modes, namely, 3-3 and 3-1.

Theoretical as well as experimental studies were carried out by using these actuators to examine their performances in smart structure applications. Azzouz et al. [4] analysed the smart laminated plates, incorporating AFC and MFC actuators using a three-node shallow shell element. The actuator ability to couple the induced strain with that of the elastic bending and twisting was further evaluated. Ruggiero et al. [5] developed SISO and MIMO based active vibration control concepts for large inflatable space structures using MFCs as sensors and actuators. Further it was shown that these techniques could identify and control the undesired vibration of flexible structure in real time. Sodano et al. [6] experimentally investigated the use of MFC 3-3 actuators in the active vibration control of inflatable structure. The relevance of these actuators (MFCs) in self-sensing actuation mode was demonstrated through an experiment on beam structure.

Park and Kim [7] reported the merits of single crystal PZT fibers with respect to polycrystalline fibers, based on the analytical results. Using classical lamination theory (CLT) and uniform fields model (UFM), the effective properties of single crystal MFC were derived. Subsequently an analytical model of this device was developed and used in the simulation of an active twist rotor blade. There have been studies appeared in the literatures which discuss about the nonlinear aspect of induced actuation to the applied field and characterisation procedures of AFCs and MFCs.

The piezoelectric fiber composite actuators (AFC, MFC) couple an applied electric field with the normal strain fields (along $x$, or $y$, or both). They are capable of developing predominantly bending deformation and moderately torsion, if the fibers are directionally oriented. In order to build optimally actuated smart laminated and sandwich 
structures, it is appropriate to introduce the induced strains by coupling the applied electric field(s) to both normal strain and shear strain fields. Many attempts were made to study the shear actuated smart structures using monolithic shear piezoelectric crystals. The salient features such as modelling of shear actuation in beams, plates, and shells with bending behaviour and vibration control aspects were already dealt with. A very few experimental studies were also reported, showing the significance of shear actuators in the vibration control applications [8-14].

The shear actuation is induced by a very high piezoelectric coupling coefficient, and it couples the transverse shear strain fields directly. It therefore can able to behave as an efficient torsional actuator. The shear actuation may also develop better active damping due to its local shear effect. Despite the above facts, shear actuation is not much popular due to the manufacturing constraints and structural integrity issues (cracks, fatigue, damage tolerance, etc). The conformability is a critical problem to use the flat monolithic shear actuators with the curved laminated and/or sandwich panels. In order to develop a directional actuation, the monolithic shear actuator needs to be positioned with an angle on the substrate. Indeed this arrangement may not induce the transverse shear strains effectively. Thus, recently Raja and Ikeda have proposed a shear actuated fiber composite (SAFC), which can able to couple simultaneously both transverse shear strains with the applied electric field [15].

A vibrating structure may develop normal and shear strain fields. The torsion mode gets critically influenced by shear strains, which may couple with bending strain under the influence of aerodynamic forces. The structural interactions with the aerodynamic forces may cause dynamic stability (flutter of lifting surfaces) and response related problems (buffeting of fin, wing, etc). The dynamic stability of structure is normally damping dependent. On the other hand, the structural response is highly influenced by the amplitude of disturbing force. Therefore, it is appropriate to optimally induce the piezoelectric strains in order to have a maximized control performance using MFC and SAFC actuators with a minimum control effort. Hence, the focus of the present work is to address the importance of coupling both normal strain fields and shear strain fields of the laminated structures with the piezoelectrically induced strains. In the process, the use of MFC and SAFC actuators is demonstrated with deflection and control applications. A systematic attempt is made first to study the bending behaviour of SAFC actuated sandwich and laminated structures. The orientation of active fiber and actuator width are considered as design parameters. Subsequently the static and active vibration control studies are performed to evaluate the effectiveness of the extension actuated (MFC) and shear actuated (SAFC) piezoelectric composites. Closed loop damping has been considered as a parameter to assess actuator performance in controlling bending and torsion vibrations. The numerical study has employed a first-order shear deformable Mindlin plate element that is capable of modelling both in-plane electric field (along $x$-direction) and transverse electric field (along $z$-direction) to account for extension and thickness shear actuation modes in laminated and sandwich structures.

\section{Structural Modelling}

2.1. Electroelastic Energy Formulation. Assume that a laminated plate contains two active composite layers, namely, MFC 3-3 and SAFC to simulate the two actuation modes. The piezoelectric composite actuators are further assumed to develop coupling between elastic and electric fields under the electro-mechanical loadings. The following constitutive equations are employed to capture the direct (sensing) and converse (actuation) effects:

$$
\begin{aligned}
& \{\sigma\}=[c]\{\varepsilon\}-[e]^{T}\{E\}, \\
& \{D\}=[e]\{\varepsilon\}+[\in]\{E\} .
\end{aligned}
$$

The work done by the piezoelectric composite actuators in an active laminate is derived from the stress equation of motion,

$$
\begin{aligned}
\delta U_{a}= & \int_{v}\left(\{\delta u\}^{T} \rho\{\ddot{u}\}+\{\delta \varepsilon\}^{T}\{\sigma\}\right) d v \\
& -\int_{v}\left(\{\delta u\}^{T}\left\{f_{b}\right\}\right) d v-\int_{s}\left(\{\delta u\}^{T}\left\{f_{s}\right\}\right) d s .
\end{aligned}
$$

Similarly, the work done by the piezoelectric sensor is obtained from the equation of electrostatic,

$$
\delta U_{s}=\int_{v}\left(\{\delta E\}^{T}\{D\}\right) d v-\int_{s}(q \delta \phi) d s .
$$

Thus, the generalized weak formulation of coupled electromechanical problem can be derived as

$$
\begin{gathered}
\delta U_{a}+\delta U_{s}=0 \\
\int_{v}\left[\left(\{\delta u\}^{T} \rho\{\ddot{u}\}\right)+\left(\{\delta \varepsilon\}^{T}[c]\{\varepsilon\}\right)+\left(\{\delta \varepsilon\}^{T}[e]\{E\}\right)\right. \\
\left.+\left(\{\delta E\}^{T}[e]^{T}\{\varepsilon\}\right)-\left(\{\delta E\}^{T}[\in]\{E\}\right)\right] d v \\
=\int_{s}\left(\{\delta u\}^{T}\left\{f_{s}\right\}\right) d s+\int_{s}(q \delta \phi) d s .
\end{gathered}
$$

Note that in the present formulation the body force is neglected. The energy equation (4) is discretized using the isoparametric finite element procedures to solve for the induced actuation, sensing, and elastic filed variables.

2.2. Constitutive Relations for Piezoelectric Composites. The stress-strain relation (plane stress case) is presented for a shear actuated lamina, considering the applied electric field only in the transverse direction [15]:

$$
\left\{\begin{array}{c}
\sigma_{1} \\
\sigma_{2} \\
\tau_{23} \\
\tau_{31} \\
\tau_{12} \\
D_{3}
\end{array}\right\}=\left[\begin{array}{cccccc}
Q_{11} & Q_{12} & 0 & 0 & 0 & 0 \\
Q_{12} & Q_{22} & 0 & 0 & 0 & 0 \\
0 & 0 & Q_{44} & 0 & 0 & 0 \\
0 & 0 & 0 & Q_{55} & 0 & -Q_{\mathrm{PE} 35} \\
0 & 0 & 0 & 0 & Q_{66} & 0 \\
0 & 0 & 0 & Q_{\mathrm{PE} 35} & 0 & Q_{\mathrm{DE} 33}
\end{array}\right]\left\{\begin{array}{c}
\varepsilon_{1} \\
\varepsilon_{2} \\
\gamma_{23} \\
\gamma_{31} \\
\gamma_{12} \\
E_{3}
\end{array}\right\},
$$


where

$$
\begin{aligned}
& Q_{11}=c_{11}-\frac{c_{13} c_{13}}{c_{33}}, \quad Q_{12}=c_{12}-\frac{c_{13} c_{23}}{c_{33}}, \\
& Q_{22}=c_{22}-\frac{c_{23} c_{23}}{c_{33}}, \quad Q_{44}=c_{44}, \\
& Q_{55}=c_{55}, \quad Q_{66}=c_{66}, \\
& Q_{\mathrm{PE} 35}=e_{35}, \quad Q_{\mathrm{DE} 33}=\epsilon_{33} .
\end{aligned}
$$

The subscripts PE and DE in (5) denote piezoelectric and dielectric, respectively.

The off-axis property is obtained as

$$
\left\{\begin{array}{c}
\sigma_{x} \\
\sigma_{y} \\
\tau_{x y} \\
\tau_{y z} \\
\tau_{z x} \\
D_{z}
\end{array}\right\}=\left[\begin{array}{cccccc}
\bar{Q}_{11} & \bar{Q}_{12} & \bar{Q}_{16} & 0 & 0 & 0 \\
\bar{Q}_{12} & \bar{Q}_{22} & \bar{Q}_{26} & 0 & 0 & 0 \\
\bar{Q}_{16} & \bar{Q}_{26} & \bar{Q}_{66} & 0 & 0 & 0 \\
0 & 0 & 0 & \bar{Q}_{44} & \bar{Q}_{45} & -\bar{Q}_{\mathrm{PE} 34} \\
0 & 0 & 0 & \bar{Q}_{45} & \bar{Q}_{55} & -\bar{Q}_{\mathrm{PE} 35} \\
0 & 0 & 0 & \bar{Q}_{\mathrm{PE} 34} & \bar{Q}_{\mathrm{PE} 35} & \bar{Q}_{\mathrm{DE} 33}
\end{array}\right]\left\{\begin{array}{c}
\varepsilon_{x} \\
\varepsilon_{y} \\
\gamma_{x y} \\
\gamma_{y z} \\
\gamma_{z x} \\
E_{z}
\end{array}\right\},
$$

where $\left[\bar{Q}_{i j}\right]=[T]^{T}\left[Q_{i j}\right][T], T$ is the transformation matrix.

In (7) the transformed elastic constants are well known [16], and therefore only the piezoelectric coupling constants are presented here:

$$
\begin{gathered}
\bar{Q}_{\mathrm{PE} 34}=n Q_{\mathrm{PE} 35}, \quad \bar{Q}_{\mathrm{PE} 35}=m Q_{\mathrm{PE} 35}, \quad \bar{Q}_{\mathrm{DE} 33}=Q_{\mathrm{DE} 33}, \\
m=\cos \theta, \quad n=\sin \theta \\
\theta=\text { angle of actuation and/or fiber orientation. }
\end{gathered}
$$

The stress-strain relation (plane stress case) is presented for an extension actuated lamina, considering only the applied electric field along $x$-direction:

$$
\left\{\begin{array}{c}
\sigma_{1} \\
\sigma_{2} \\
\tau_{23} \\
\tau_{31} \\
\tau_{12} \\
D_{1}
\end{array}\right\}=\left[\begin{array}{cccccc}
Q_{11} & Q_{12} & 0 & 0 & 0 & -Q_{P E 11} \\
Q_{12} & Q_{22} & 0 & 0 & 0 & -Q_{P E 12} \\
0 & 0 & Q_{44} & 0 & 0 & 0 \\
0 & 0 & 0 & Q_{55} & 0 & 0 \\
0 & 0 & 0 & 0 & Q_{66} & 0 \\
Q_{P E 11} & Q_{P E 12} & 0 & 0 & 0 & Q_{D E 11}
\end{array}\right]\left\{\begin{array}{c}
\varepsilon_{1} \\
\varepsilon_{2} \\
\gamma_{23} \\
\gamma_{31} \\
\gamma_{12} \\
E_{1}
\end{array}\right\},
$$

where

$$
\begin{aligned}
& Q_{11}=c_{11}-\frac{c_{13} c_{13}}{c_{33}}, \quad Q_{12}=c_{12}-\frac{c_{13} c_{23}}{c_{33}}, \\
& Q_{22}=c_{22}-\frac{c_{23} c_{23}}{c_{33}}, \quad Q_{44}=c_{44}, \\
& Q_{55}=c_{55}, \quad Q_{66}=c_{66}, \\
& Q_{\mathrm{PE} 11}=e_{11}-\frac{c_{13} e_{13}}{c_{33}}, \quad Q_{\mathrm{PE} 12}=e_{12}-\frac{c_{23} e_{13}}{c_{33}}, \\
& Q_{\mathrm{DE} 11}=\epsilon_{11}+\frac{e_{13} e_{13}}{c_{33}} .
\end{aligned}
$$

The off-axis property is then obtained as

$$
\left\{\begin{array}{c}
\sigma_{x} \\
\sigma_{y} \\
\tau_{x y} \\
\tau_{y z} \\
\tau_{z x} \\
D_{x}
\end{array}\right\}=\left[\begin{array}{cccccc}
\bar{Q}_{11} & \bar{Q}_{12} & \bar{Q}_{16} & 0 & 0 & -\bar{Q}_{\mathrm{PE} 11} \\
\bar{Q}_{12} & \bar{Q}_{22} & \bar{Q}_{26} & 0 & 0 & -\bar{Q}_{\mathrm{PE} 12} \\
\bar{Q}_{16} & \bar{Q}_{26} & \bar{Q}_{66} & 0 & 0 & -\bar{Q}_{\mathrm{PE} 16} \\
0 & 0 & 0 & \bar{Q}_{44} & \bar{Q}_{45} & 0 \\
0 & 0 & 0 & \bar{Q}_{45} & \bar{Q}_{55} & 0 \\
\bar{Q}_{\mathrm{PE} 11} & \bar{Q}_{\mathrm{PE} 12} & \bar{Q}_{\mathrm{PE} 16} & 0 & 0 & \bar{Q}_{\mathrm{DE} 11}
\end{array}\right]\left\{\begin{array}{c}
\varepsilon_{x} \\
\varepsilon_{y} \\
\gamma_{x y} \\
\gamma_{y z} \\
\gamma_{z x} \\
E_{x}
\end{array}\right\} .
$$

In (11), the transformed elastic constants can be referred to [16], and the piezoelectric coupling constants are given below:

$$
\begin{aligned}
& \bar{Q}_{\mathrm{PE} 11}=m^{2} Q_{\mathrm{PE} 11}+n^{2} Q_{\mathrm{PE} 12}, \\
& \bar{Q}_{\mathrm{PE} 12}=n^{2} Q_{\mathrm{PE} 11}+m^{2} Q_{\mathrm{PE} 12}, \\
& \bar{Q}_{\mathrm{DE} 11}=Q_{\mathrm{DE} 11} .
\end{aligned}
$$

2.3. Finite Element Formulation. The strain-displacement relations with reference to first-order shear deformation theory are presented for a Mindlin plate element, assuming that the laminate is relatively thin as follows:

$$
\begin{gathered}
\{\varepsilon\}=\left\{\begin{array}{l}
\varepsilon_{x} \\
\varepsilon_{y} \\
\gamma_{x y} \\
\gamma_{y z} \\
\gamma_{z x}
\end{array}\right\}=\left[\begin{array}{ccccc}
\frac{\partial}{\partial x} & 0 & 0 & 0 & z \frac{\partial}{\partial x} \\
0 & \frac{\partial}{\partial y} & 0 & -z \frac{\partial}{\partial y} & 0 \\
\frac{\partial}{\partial y} & \frac{\partial}{\partial x} & 0 & -z \frac{\partial}{\partial x} & z \frac{\partial}{\partial y} \\
0 & 0 & \frac{\partial}{\partial y} & -1 & 0 \\
0 & 0 & \frac{\partial}{\partial x} & 0 & 1
\end{array}\right]\left\{\begin{array}{l}
u_{0} \\
v_{0} \\
w_{0} \\
\theta_{x} \\
\theta_{y}
\end{array}\right\}, \\
\{E\}=\left\{\begin{array}{c}
E_{x} \\
E_{z}
\end{array}\right\}=\left[\begin{array}{cc}
-\frac{1}{W_{e}} & 0 \\
0 & -\frac{1}{h_{a}}
\end{array}\right]\left\{\begin{array}{l}
\phi_{x} \\
\phi_{z}
\end{array}\right\},
\end{gathered}
$$

where $w_{e}$ is the distance between the two finger electrodes and $h_{a}$ is the thickness of active lamina (refer to Figure 1).

In $(13), u_{0}(x, y), v_{0}(x, y)$, and $w_{0}(x, y)$ are the midplane displacements $(z=0)$ and $\theta_{x}(x, y), \theta_{y}(x, y)$ are the cross-sectional rotations of $y z$ and $z x$ planes, respectively. The electric nodal parameters $\phi_{x}, \phi_{z}$ are the difference of potentials along $x$ - and $z$-directions, respectively.

The field variables (displacements and difference of potentials) are isoparametrically interpolated within the element domain ( $\xi=-1$ to $1 ; \eta=-1$ to 1$)$. The isoparametric coordinates $(\xi, \eta)$ are subsequently related to the global structural coordinates $(x, y, z)$ through Jacobian as follows:

$$
\left\{u^{e} \phi^{e}\right\}^{T}=\sum_{i=1,4} N_{i}\{\bar{u}, \bar{\phi}\}_{i}^{T}
$$



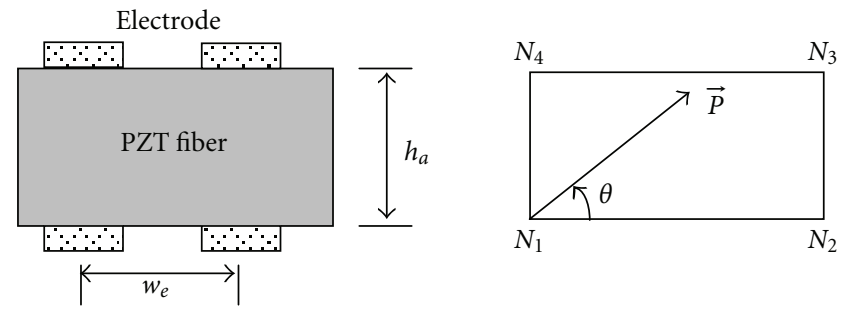

(a) Electrode details of MFC and SAFC

(b) Actuation orientation in element

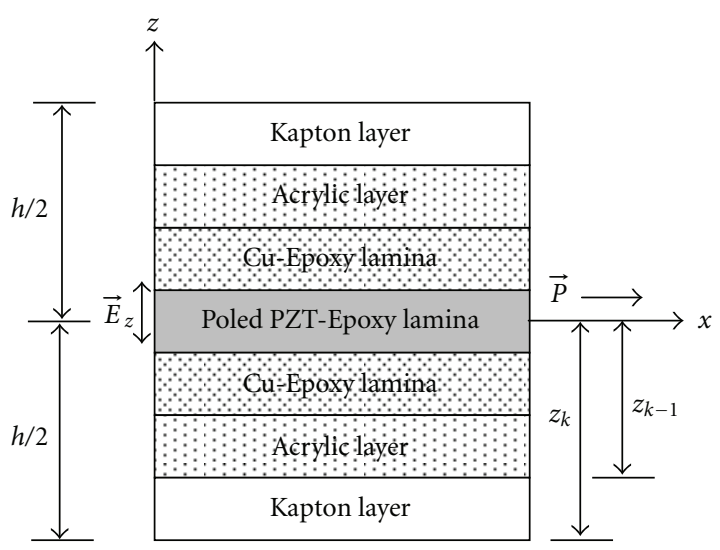

(c) SAFC [15]

FIgURE 1: MFC and SAFC modeling details.

where $\{\bar{u}\}_{i}=\left\{u_{0}, v_{0}, w_{0}, \theta_{x}, \theta_{y}\right\}^{T},\{\bar{\phi}\}_{i}=\left\{\phi_{x}, \phi_{z}\right\}^{T}$ are the nodal vectors of mechanical and electric degrees of freedom, respectively, at the $i$ th node and $N_{i}$ are the isoparametric shape functions.

Therefore, the gradient relations are expressed in terms of nodal parameters as

$$
\left\{\mathcal{\varepsilon}^{e}\right\}=\sum_{i=1,4}[J]_{i}^{-1}\left[B_{u}\right]_{i}\{\bar{u}\}_{i}, \quad\left\{E^{e}\right\}=\sum_{i=1,4}[J]_{i}^{-1}\left[B_{\phi}\right]_{i}\{\bar{\phi}\}_{i} .
$$

In (14) and (15), superscript " $e$ " defines the element domain, $[J]$ is a Jacobian matrix, and $\left[B_{u}\right],\left[B_{\phi}\right]$ are the shape function derivative matrices of elastic and electric fields, respectively.

By substituting (14) and (15) together with the material constitutive relations $((7),(11))$ in (4), the equilibrium equations are obtained. They are expressed in matrix form as follows:

$$
\begin{gathered}
{\left[M_{u u}\right]\{\ddot{\bar{u}}\}+\left[K_{u u}\right]\{\bar{u}\}+\left[K_{u \phi}\right]\{\bar{\phi}\}=\{F\},} \\
{\left[K_{\phi u}\right]\{\bar{u}\}+\left[K_{\phi \phi}\right]\{\bar{\phi}\}=0,}
\end{gathered}
$$

where $F$ is the applied mechanical disturbance.

The electric potentials can be imposed as boundary conditions, while solving the actuator equation (16).
The element matrices are computed using the following relations:

$$
\begin{aligned}
& {\left[M_{u u}^{e}\right]=\iint\left[N_{u}\right]^{T}[\bar{\rho}]\left[N_{u}\right]|J| d \xi d \eta,} \\
& {\left[K_{u u}^{e}\right]=\iint\left[B_{u}\right]^{T}[\bar{c}]\left[B_{u}\right]|J| d \xi d \eta,} \\
& {\left[K_{u \phi}^{e}\right]=\iint\left[B_{u}\right]^{T}[\bar{e}]\left[B_{\phi}\right]|J| d \xi d \eta,} \\
& {\left[K_{\phi \phi}^{e}\right]=\iint\left[B_{\phi}\right]^{T}[\bar{\epsilon}]\left[B_{\phi}\right]|J| d \xi d \eta,} \\
& {\left[K_{\phi u}^{e}\right]=\iint\left[B_{\phi}\right]^{T}[\bar{e}]^{T}\left[B_{u}\right]|J| d \xi d \eta .}
\end{aligned}
$$

The material constitutive matrices are defined by

$$
\begin{gathered}
{[\bar{c}]=\left[\begin{array}{ccc}
A^{E} & B^{E} & 0 \\
B^{E} & D^{E} & 0 \\
0 & 0 & A^{S}
\end{array}\right], \quad[\bar{e}]=\left[\begin{array}{cc}
A^{\mathrm{PE}} & 0 \\
B^{\mathrm{PE}} & 0 \\
0 & A^{\mathrm{PE}}
\end{array}\right],} \\
{[\bar{\epsilon}]=\left[\begin{array}{cc}
A^{\mathrm{DE}} & 0 \\
0 & A^{\mathrm{DE}}
\end{array}\right],} \\
A_{i j}^{E}=\sum_{k=1}^{n}\left(\bar{Q}_{i j}\right)_{k}\left(z_{k}-z_{k-1}\right), \quad i, j=1,2,6, \\
B_{i j}^{E}=\frac{1}{2} \sum_{k=1}^{n}\left(\bar{Q}_{i j}\right)_{k}\left(z_{k}^{2}-z_{k-1}^{2}\right), \quad i, j=1,2,6, \\
D_{i j}^{E}=\frac{1}{3} \sum_{k=1}^{n}\left(\bar{Q}_{i j}\right)_{k}\left(z_{k}^{3}-z_{k-1}^{3}\right), \quad i, j=1,2,6, \\
A_{i j}^{S}=\sum_{k=1}^{n}\left(\bar{Q}_{i j}\right)_{k}\left(z_{k}-z_{k-1}\right), \quad i, j=4,5, \\
A_{i j}^{\mathrm{PE}}=\sum_{k=1}^{n}\left(\bar{Q}_{\mathrm{PE} i j}\right)_{k}\left(z_{k}-z_{k-1}\right), \quad i=1, \\
j=1,2,6 ; \quad i=3, \quad j=4,5, \\
A_{i j}^{\mathrm{DE}}=\sum_{k=1}^{n}\left(\bar{Q}_{\mathrm{DE} i j}\right)_{k}\left(z_{k}-z_{k-1}\right), \quad i, j=1,3,
\end{gathered}
$$

where superscript $s$ denotes shear and $E, \mathrm{PE}$ and DE define elastic, piezoelectric, and dielectric, respectively.

The mass property is

$$
[\bar{\rho}]=\left[\begin{array}{ccccc}
I_{n} & 0 & 0 & 0 & 0 \\
0 & I_{n} & 0 & 0 & 0 \\
0 & 0 & I_{n} & 0 & 0 \\
0 & 0 & 0 & I_{r} & 0 \\
0 & 0 & 0 & 0 & I_{r}
\end{array}\right], \quad\left(I_{n}, I_{r}\right)=\sum_{k=1}^{n} \int_{z_{k-1}}^{z_{k}} \rho_{k}\left(1, z^{2}\right) d z .
$$

The procedure to evaluate the material constants of laminated composites has been followed from [16]. 


\section{Active Control Procedure}

A simplified control approach has been adopted in the present analysis. The closed loop system is built with a fullstate feedback controller, which assumes that all the states of a vibrating system are available. However, in practice to implement this controller, a Kalman filter (state estimator) is required. Nevertheless, the focus of the present paper is to bring out the important aspects of MFC and SAFC actuators in controlling bending and torsion modes of the laminated plate structures. A linear quadratic regulator design (MATLAB: "lqr.m" function) is implemented in modal domain, targeting the bending and torsion modes.

The physical coordinate-to-modal coordinate relation is taken as $\bar{u}=\Phi \psi$. Further the plant (elastic plate) is assumed to be disturbed externally by a mechanical force. The dynamic equation of the plate with built-in actuators may be presented in modal domain as

$$
\ddot{\psi}+2 \zeta \omega \dot{\psi}+\omega^{2} \psi=b \phi_{a}+f
$$

where $b=[\Phi]^{T}\left[K_{u \phi}\right], \Phi(n \times n)$ is a modal matrix $K_{u \phi}(n \times$ $a)$ is the actuator sensitivity matrix " $a$ " is the number of actuators, and $f=[\Phi]^{T}\{F\}$ is the modal disturbance force.

Subsequently, (21) can be written in a state variable form using two new state variables $\{\chi\}=\left\{\begin{array}{ll}\chi_{1} & \chi_{2}\end{array}\right\}^{T}$ as

$$
\dot{\chi}=A \chi+B \phi_{a}
$$

where $\chi_{1}=\psi, \chi_{2}=\dot{\psi}$.

The modal state-space matrices for the $i$ th mode are obtained as follows:

$$
\left[A_{i}\right]=\left[\begin{array}{cc}
0 & 1 \\
-\omega_{i}^{2} & -2 \zeta_{i} \omega_{i}
\end{array}\right] ; \quad\left[B_{i}\right]=\left[\begin{array}{cc}
0 & 0 \\
f(i) & b(i, a)
\end{array}\right] .
$$

A linear feedback control $\phi_{a}=-k x$ has been adopted. The modal gain $(k)$ is further computed by solving the algebraic Riccati equation such that the system is stable in an infinite time domain. The details of the modal control approach are already presented by Raja et al. [12].

The actuator voltage $\left(\phi_{a}\right)$ is finally estimated for the $n$th patch to control the $i$ th mode using the following relation:

$$
\phi_{a i}^{n}=-k_{i}^{d} \frac{1}{C_{P}^{n}} K_{\phi u}^{n} \Phi_{i} \psi_{i}-k_{i}^{v} R_{e} K_{\phi u}^{n} \Phi_{i} \dot{\psi}_{i}
$$

where $k_{i}^{d}$ is the displacement feedback gain, $k_{i}^{v}$ is the velocity feedback gain, $C_{P}^{n}$ is the capacitance of the $n$th actuator patch, $R_{e}$ is the equivalent circuit resistance, $K_{\phi u}$ is the sensor influence matrix, and $\psi, \dot{\psi}$, are the modal displacement and velocity, respectively.

The equivalent circuit resistance is selected $\left(C_{P}^{n} R_{e}=\Delta t\right)$, assuming the sampling time as $\Delta t=0.001$ seconds. The structural and control analyses are performed in MATLAB platform. In the control simulation, the applied voltages introduce feedback forces into the vibrating plate, which will be the function of displacement and velocity gains.

\section{Numerical Analysis}

The main emphasis in the present work is to numerically evaluate the performance of extension actuated MFC and shear actuated SAFC in deflection and structural control applications. This has been achieved through systematic case studies carried out as follows.

(i) First, the developed finite element is validated for modelling the extension and shear actuated piezoelectric composites.

(ii) The numerical model is then used to generate the bending behaviour of smart sandwich and laminated plates with embedded SAFC actuators. This is done to observe the deflection ability of the shear actuated composite.

(iii) Finally an active vibration control study has been performed on a laminated plate with MFC and SAFC actuators.

Since MFC and SAFC are in device form, a laminate ideology is adopted to estimate the equivalent elastic and piezoelectric properties [15]. The MFC M4010-P1 of Smart Materials is used in the analysis and experiment. The same dimension is used for the design of SAFC (seven-layered configuration; see Figure 1), except for the active PZT-Epoxy lamina.

4.1. Validation Studies. The developed numerical model is validated for its capability to capture the coupling of an in-plane electric field (MFC) to normal strains and the transverse electric field (SAFC) to shear strains. A constant electric field is considered in the simulation of both MFC and SAFC because of linear potential assumption made in the formulation. The MFC modelling is checked with the help of an experiment, conducted on a Aluminium beam. The beam is fabricated with a surface-bonded MFC (M4010-P1), and the details of the beam is given in Figure 2. In addition to this actuator, a PZT patch is bonded on the other side of the beam and a strain gage is fixed beside the actuator.

The deflection measurement is done with the help of a laser sensor, which has got a sensitivity of $20 \mu \mathrm{m}$ (refer to Figure 3). The tip displacements for different applied voltages ( 0 to 1000 volts; 1000 to 0 volts) are measured. In Figure 4, the displacements of the forward path are depicted along with the numerically computed ones. The finite element model is made with a nonuniform mesh $(12 \times 3)$ to accommodate the active area of MFC $(40 \times$ $\left.10 \mathrm{~mm}^{2}\right)$. A deviation of 5 to $10 \%$ is seen beyond 500 volt DC from theory to experiment. It certainly necessitates an improvement in the electric field modelling for higher field simulation. Therefore in the numerical analysis, the applied voltage is restricted to less than 500 volts. The consistency in the measured displacements is checked by repeating the tests, and the averaged values are taken for each applied voltage. However, in the reverse path a significant hysteresis in the actuation behaviour is noticed.

As a second case, the shear actuation modelling is performed on a clamped-free sandwich beam $[8,10,12]$. The beam is of $100 \mathrm{~mm}$ length with aluminium faces, having 

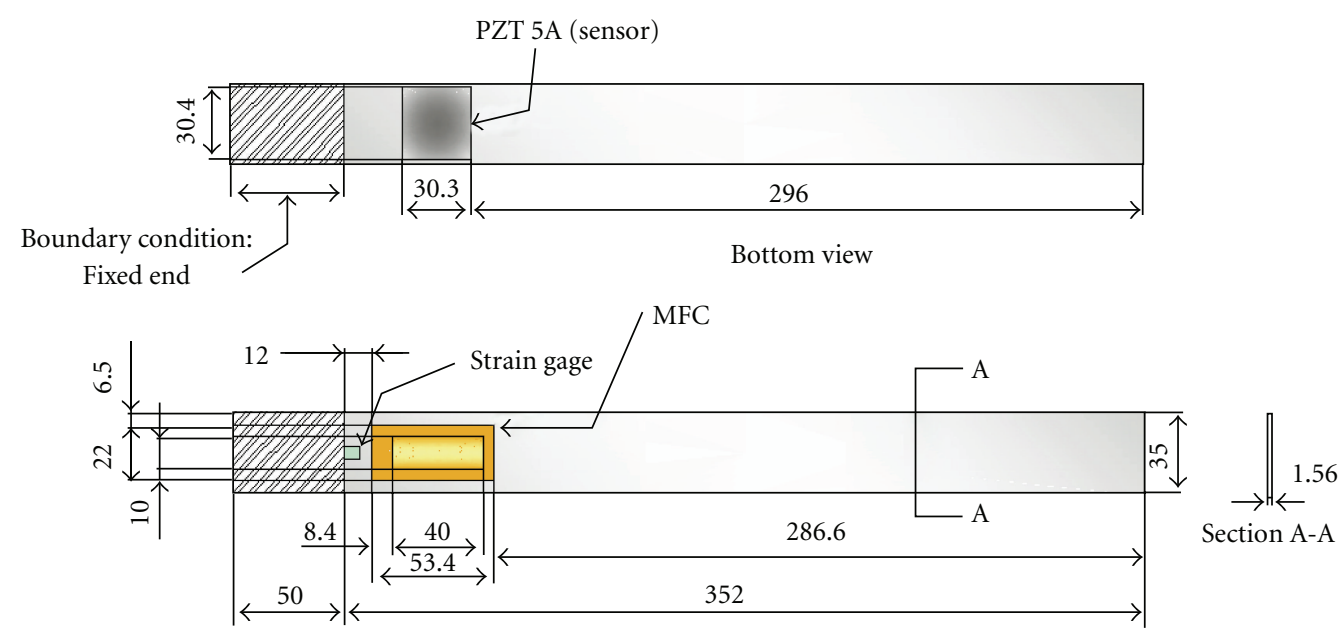

Top view

All dimension ( $\mathrm{mm})$

FIGURE 2: Clamped-free AL beam with surface bonded MFC actuator and sensor.

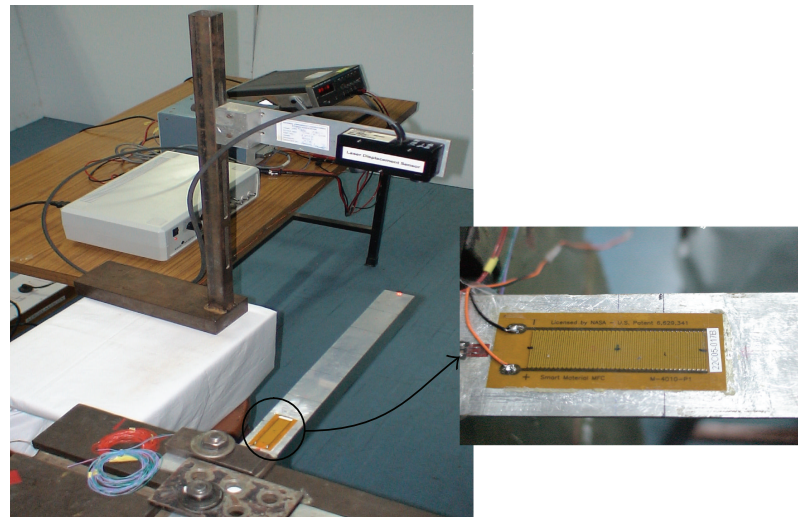

FIgURE 3: Clamped-free AL beam with surface-bonded MFC actuator under static piezoelectric testing.

$8 \mathrm{~mm}$ thickness each. A $2 \mathrm{~mm}$ thick shear piezoelectric core is sandwiched between these isotropic faces to a full length of the beam. The material data is taken from [8]. The shear core is actuated with $20 \mathrm{~V}$, and the transverse displacements along the length of the beam are computed (see Figure 5). It is evident that the three-layer theory based finite elements $[8,12]$ predict the nature of sandwich actuator better than the single-layer theory based finite elements [10, present]. Aldraihem and Khdeir [10] have discussed this issue in detail and have suggested $2 / 3$ as a shear correction factor for the shear actuated lamina to achieve a closer simulation to the three-layer theory. Accordingly, the numerical results are generated in the present work with $2 / 3$ as a shear correction factor for the SAFC actuator.

The above two case studies have validated the developed plate element to idealize both extension (MFC) and shear (SAFC) actuations.

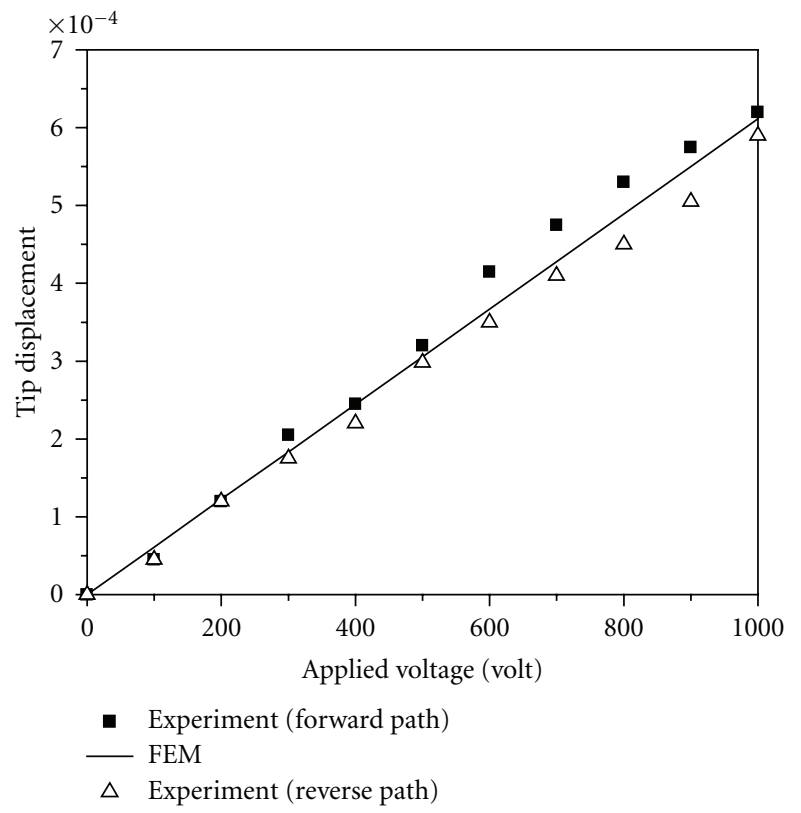

FIGURE 4: Deflection of clamped-free AL beam with surface bonded MFC (experiment and theory).

4.2. Static Behaviour of SAFC Actuated Sandwich and Laminated Plates. The deflection ability of SAFC actuator has been studied before it is employed in the active vibration control application. The influences of actuation orientation, phase of the applied voltages (positive or negative), and actuator width are considered as design parameters on the induced deformation pattern. Figure 6 presents the geometry of the plate and the actuators' locations (patch 1 and patch 2). Numerical studies are performed on the sandwich and laminated plates with embedded SAFC actuators. The finite 


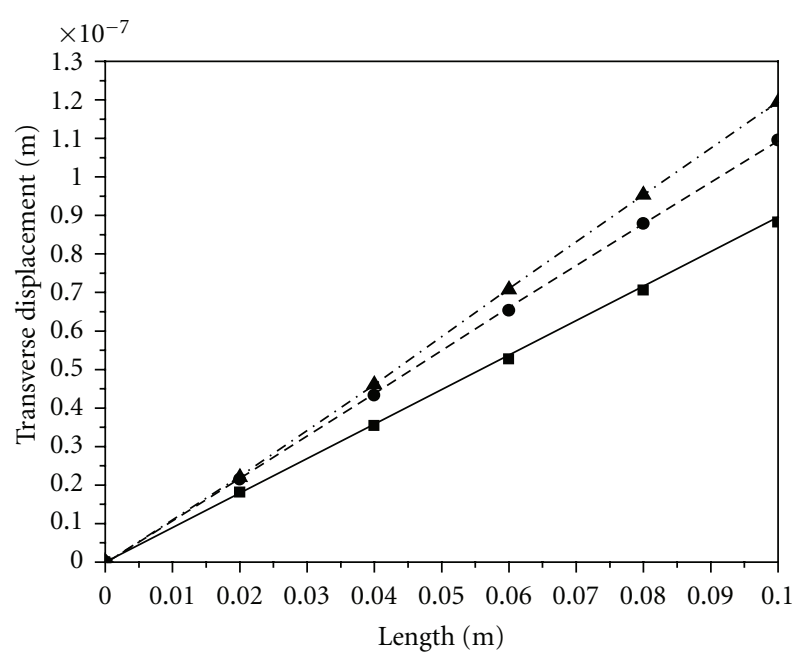

- Aldraihem and Khdeir [10]; SCF $=5 / 6$

- Aldraihem and Khdeir [10]; SCF $=2 / 3$

- 4 . Three layer theory $[8,12]$

Present $(\mathrm{SCF}=5 / 6)$

-- Present $(\mathrm{SCF}=2 / 3)$

Figure 5: Deflection of clamped-free sandwich beam with embedded shear actuator ( $e_{35}$ actuation).

element model is made with a mesh size of $32 \times 16$, and a clamped-free boundary condition is assumed in the analysis. There are four cases considered.

Case a. Aluminium $(0.3 \mathrm{~mm}) / \mathrm{SAFC}(0.9 \mathrm{~mm}) /$ aluminium $(0.3 \mathrm{~mm})$ as active part and the rest of the plate is considered as aluminium $(0.75 \mathrm{~mm})$ /aluminium $(0.75 \mathrm{~mm})$.

Case b. Cross-ply (0/90)/SAFC (0.9 mm)/cross-ply (90/0) as active part and the rest of the plate is considered as symmetric cross-ply laminate (0/90/0/90/0/0/90/0/90/0).

Case c. Angle-ply (45/-45)/SAFC (0.9 mm)/angle-ply (-45/ $45)$ as active part and the rest of the plate is taken as angle-ply laminate $(45 /-45 / 45 /-45 / 45 / 45 /-45 / 45 /-45 / 45)$.

Case d. Cross-ply (0/90)/SAFC (0.9 mm)/cross-ply (90/0) as active part and the rest of the plate is considered as cross-ply (0/90)/foam/cross-ply (90/0).

The total laminate thickness is maintained as $1.5 \mathrm{~mm}$, and CFRP (T-300) is considered with $0.15 \mathrm{~mm}$ ply thickness. 6 layers are removed from the laminate to form a slot so that SAFC can be embedded inside it. In the isotropic case $0.45 \mathrm{~mm}$ slot is assumed in each aluminium sheet at the actuator location. The material data is presented in Table 1. There are two SAFC patches considered with an active area $40 \times 10 \mathrm{~mm}^{2}$ each (refer to Figure 6). However, studies are also made with through-width actuator $(160 \mathrm{~mm})$. The actuation orientation (angle of actuation) is taken with respect to the first edge of the finite element, and the nodal connectivity is taken in anticlockwise sense (refer to Figure 1). The electromechanically induced deflection patterns for the applied voltage of 100 volts are given in Figures 7 to 14 . The following observations are made.

(i) Two cases, namely, $\theta_{1}, \theta_{2}=0^{\circ}$ and $\theta_{1}=45^{\circ}, \theta_{2}=$ $45^{\circ}$, are examined. It is seen that these angles of actuation are able to induce bending and torsion of the plate structures. The angle of actuation $0^{\circ}$ produces a better deflection performance than $45^{\circ}$.

(ii) The geometry of the PZT fiber (e.g., thickness, volume fraction, and angle of actuation) certainly plays a role in the performance of the actuator [15]. However, the phase of the applied voltage may be found equally important in the active vibration control design.

(iii) The induced deflection patterns are observed to be different for cross-ply and angle-ply laminated plates. A linear variation is observed until actuator end (along $x$ ), and, beyond this distance, the transverse displacement is nearly constant for the cross-ply laminate. In contrast, a linearly varying trend is noticed in the angle-ply laminate.

(iv) The deflection of the plate is constant beyond the shear actuator in the case of through-width actuation (160 mm).

(v) As the actuator width gets reduced, the deflection trend changes from constant to linear in the angleply laminated case.

4.3. Active Vibration Control of MFC and SAFC Actuated Laminated Plate. After assessing the deflection ability of SAFC actuators, a vibration control study is performed on a symmetric laminate with a lay-up sequence of $[0 / 90 / 0 / 45 /-45 /-45 / 45 / 0 / 90 / 0]_{T}$. The geometry of the plate has been retained as shown in Figure 6. Two segmented MFC actuators and two SAFC actuators are assumed to be surface bonded and embedded, respectively, in the laminate. As mentioned earlier, the SAFC is accommodated, by not considering 6 layers at its location to have a slot. Therefore the thickness of the active element is $1.9 \mathrm{~mm}$, and the nonactive element is $1.5 \mathrm{~mm}$. In the analysis, the poling is considered along $x$-direction. Thus, the angle of actuation is taken as $0^{\circ}$. The material data used in the analysis is presented in Table 1, and the density values are estimated for both actuators, considering all the seven layers.

A full-state feedback control design (linear quadratic regulator $(\mathrm{LQR}))$ is done in modal domain, targeting the first two modes, namely, bending and torsion. In the control gain estimation, the control input effort $(R)$ is tuned, keeping the state weighting values $(Q)$ constant. Further, to assess the performance of piezoelectric composites, the applied electric field (SAFC: applied voltage/distance between the electrodes, MFC: applied voltage/IDE distance) has been kept nearly, same for both actuation cases. The distance between the electrodes for SAFC is taken as $1.0 \mathrm{~mm}$, and the IDE distance of MFC is $0.5 \mathrm{~mm}$. The vibration control results are presented in frequency domain as well as in time domain (refer to Figures 15 to 18). Tables 2 and 3 provide the open- and closed loop systems parameters. The sine response 


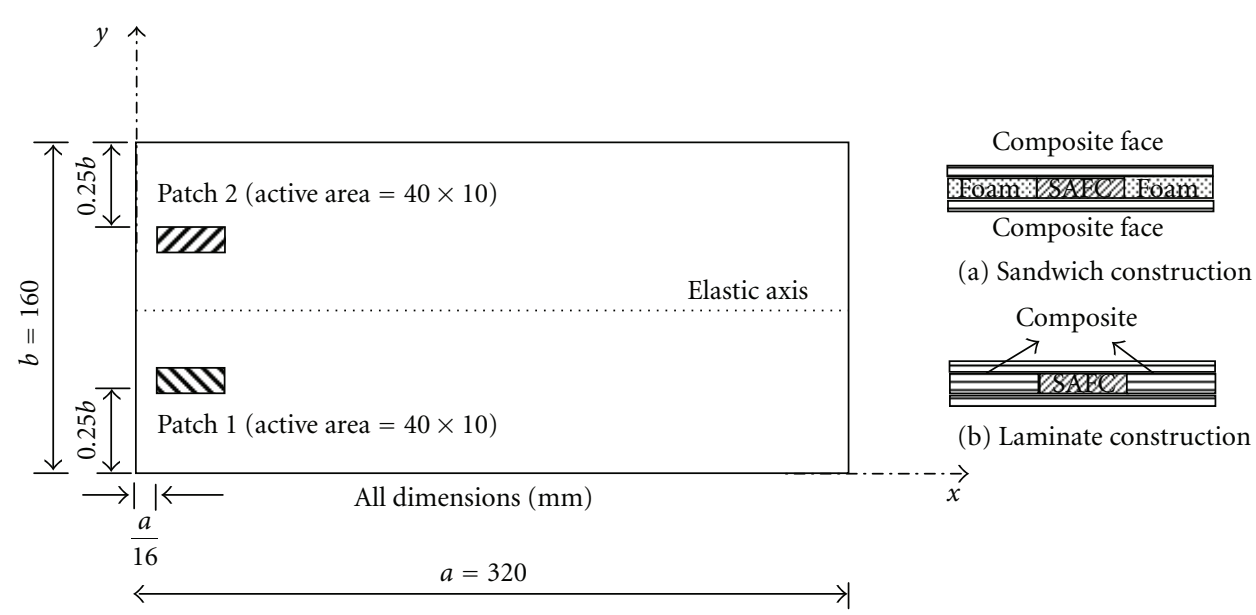

FIGURE 6: Clamped-free plate geometry with surface bonded MFC actuators and embedded SAFC actuators (same location).

TABle 1: Material data.

\begin{tabular}{|c|c|c|}
\hline Materials & Elastic property & Piezoelectric property \\
\hline \multirow{4}{*}{$\begin{array}{l}\text { PZT-5A-based SAFC* } \\
(\text { fiber content }=94 \%)\end{array}$} & $E_{1}=28.03 \mathrm{GPa}, E_{2}=52.72 \mathrm{GPa}$ & \multirow{4}{*}{$\begin{array}{l}d_{35}=542.6 \mathrm{pC} / \mathrm{N} \\
\in_{33}=18.98 \mathrm{nF} / \mathrm{m}\end{array}$} \\
\hline & $G_{12}=10.85 \mathrm{GPa}, G_{13}=10.14 \mathrm{GPa}$ & \\
\hline & $G_{23}=19.52 \mathrm{GPa}, v_{12}=0.23$ & \\
\hline & $\rho=6870.36 \mathrm{~kg} / \mathrm{m}^{3}$ & \\
\hline \multirow{4}{*}{$\begin{array}{l}\mathrm{MFC}^{*}(\mathrm{M}-4010-\mathrm{P} 1, \text { smart } \\
\text { materials) (fiber content }= \\
85 \%, h_{k}=0.3 \mathrm{~mm} ; \\
\left.w_{e}=0.5 \mathrm{~mm}\right)\end{array}$} & $E_{1}=30.25 \mathrm{GPa}, E_{2}=15.99 \mathrm{GPa}$ & \multirow{4}{*}{$\begin{array}{l}d_{11}=385.56 \mathrm{pC} / \mathrm{N} \\
d_{12}=-171.43 \mathrm{pC} / \mathrm{N} \\
\epsilon_{11}=14.3 \mathrm{nF} / \mathrm{m}\end{array}$} \\
\hline & $G_{12}=5.52 \mathrm{GPa}, G_{13}=11.82 \mathrm{GPa}$ & \\
\hline & $G_{23}=4.54 \mathrm{GPa}, v_{12}=0.306$ & \\
\hline & $\rho=5019.34 \mathrm{~kg} / \mathrm{m}^{3}$ & \\
\hline \multirow{4}{*}{ CFRP (T-300) } & $E_{1}=130.0 \mathrm{GPa}, E_{2}=9.5 \mathrm{GPa}$ & \multirow{4}{*}{ - } \\
\hline & $G_{12}=6.0 \mathrm{GPa}, G_{13}=6.0 \mathrm{GPa}$ & \\
\hline & $G_{23}=3.0 \mathrm{GPa}, v_{12}=0.3$ & \\
\hline & $\rho=1600.0 \mathrm{~kg} / \mathrm{m}^{3}$ & \\
\hline \multirow{2}{*}{ Foam } & $E=35.3 \mathrm{GPa}, v=0.383$ & \multirow{2}{*}{ - } \\
\hline & $\rho=32.0 \mathrm{~kg} / \mathrm{m}^{3}$ & \\
\hline \multirow{2}{*}{ Aluminium } & $E=70.3 \mathrm{GPa}, v=0.3$ & \multirow{2}{*}{ - } \\
\hline & $\rho=2800.0 \mathrm{~kg} / \mathrm{m}^{3}$ & \\
\hline
\end{tabular}

* Properties calculated using the rule of mixtures models.

analysis is performed by applying a $1 \mathrm{~N}$ disturbance force at $x=0.02 \mathrm{~m}, y=0.13 \mathrm{~m}$ and the corresponding response is computed at $x=0.32 \mathrm{~m}, y=0.0 \mathrm{~m}$. The disturbance force is assumed to be cut-off after $t=0.5 \mathrm{sec}$, for the system to freely decay. The actuators MFC and SAFC are considered to be working independently. The applied voltages are taken inphase for bending mode control and opposite in the case of torsion mode. Figures 15 and 17 are corresponding to SAFC in operation and Figures 16 and 18 are those while MFC actuators functioning. In the active control analysis, $1 \%$ and $0.5 \%$ open-loop damping is assumed for bending and torsion modes, respectively.

It is evident from the results that the piezoelectric composite actuators are efficiently controlling the bending and torsion modes. However, the performance of these actuators is observed to be interesting. Nearly the same electric field is maintained to assess the actuation performances of MFC and SAFC actuators. This is achieved by fine tuning the weighted values of $(R)$ in the LQR design. The closed loop damping is inclusive of the assumed structural damping (open loop). For the zero angle of actuation, the SAFC actuators (patches 1,2) have produced $5.89 \%$ and $1.48 \%$ damping for the bending and torsion modes, respectively. In contrast, the MFC actuators have developed $3.51 \%$ and $1.15 \%$ for the first and second modes, respectively. Therefore, it is apparent that the electromechanically induced extension-bending coupling is certainly advantageous from the deflection performance point of view [4] and appreciably good in the active vibration control application (refer to Table 2). But the electromechanically induced shear-bending coupling shows 


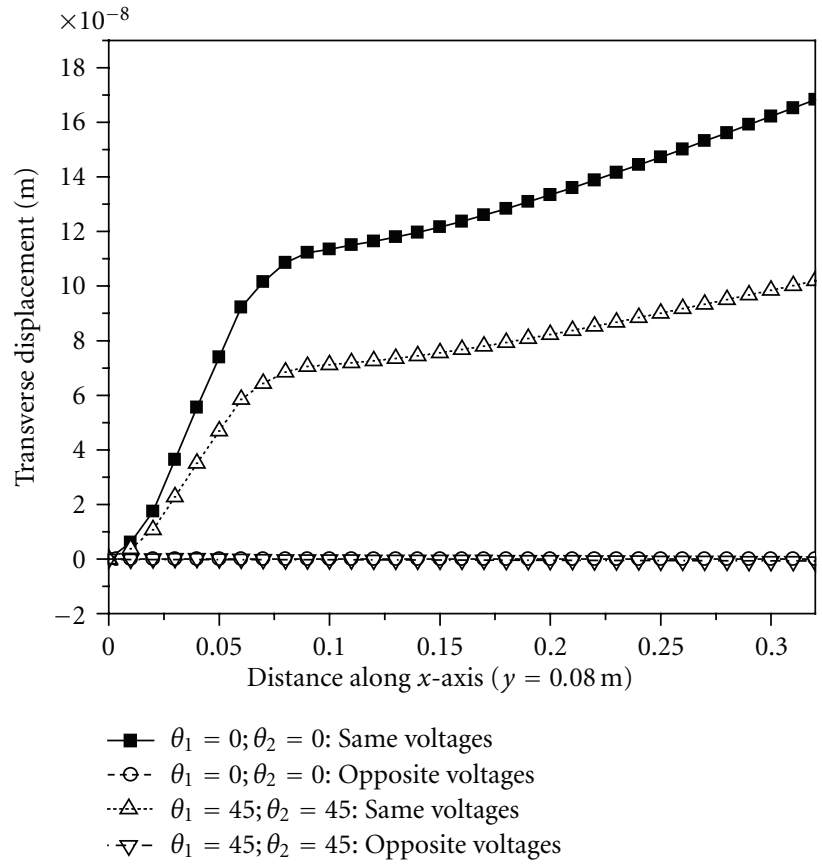

(a)

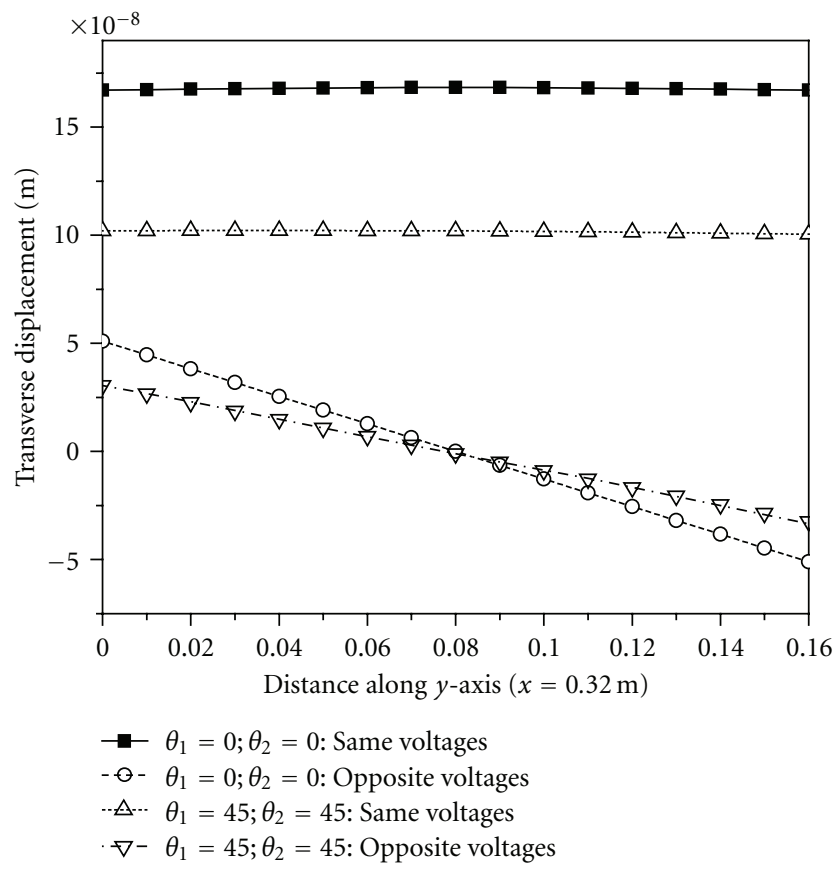

(b)

FIGURE 7: Clamped-free isotropic layered plate with embedded SAFC actuators; passive element: [AL/AL]; active element: [AL/SAFC/AL].

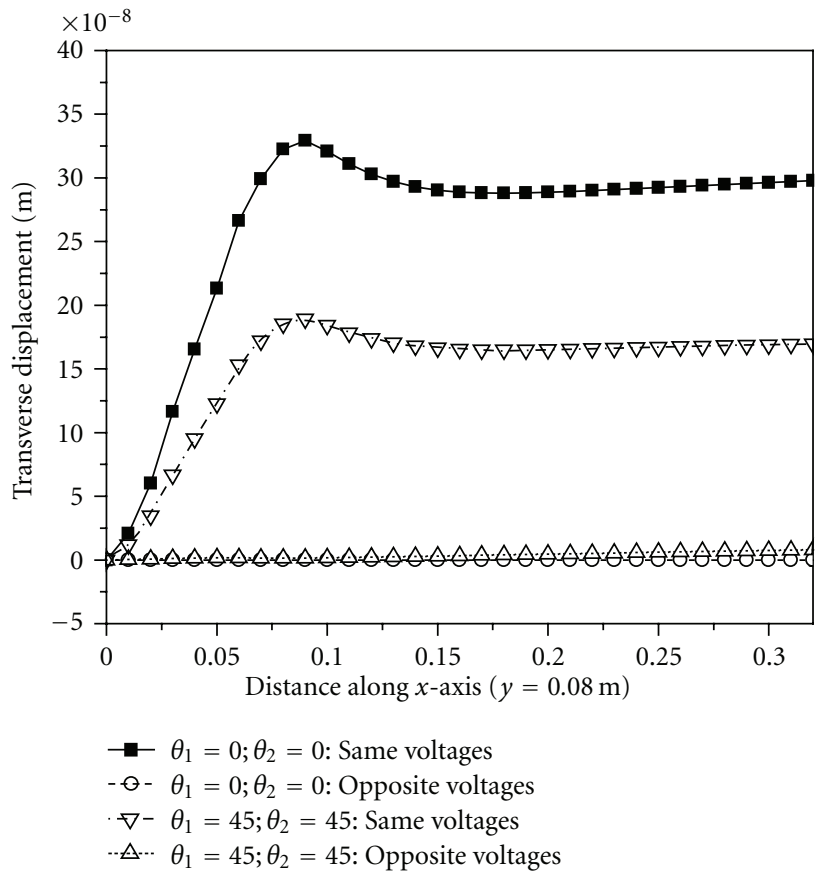

(a)

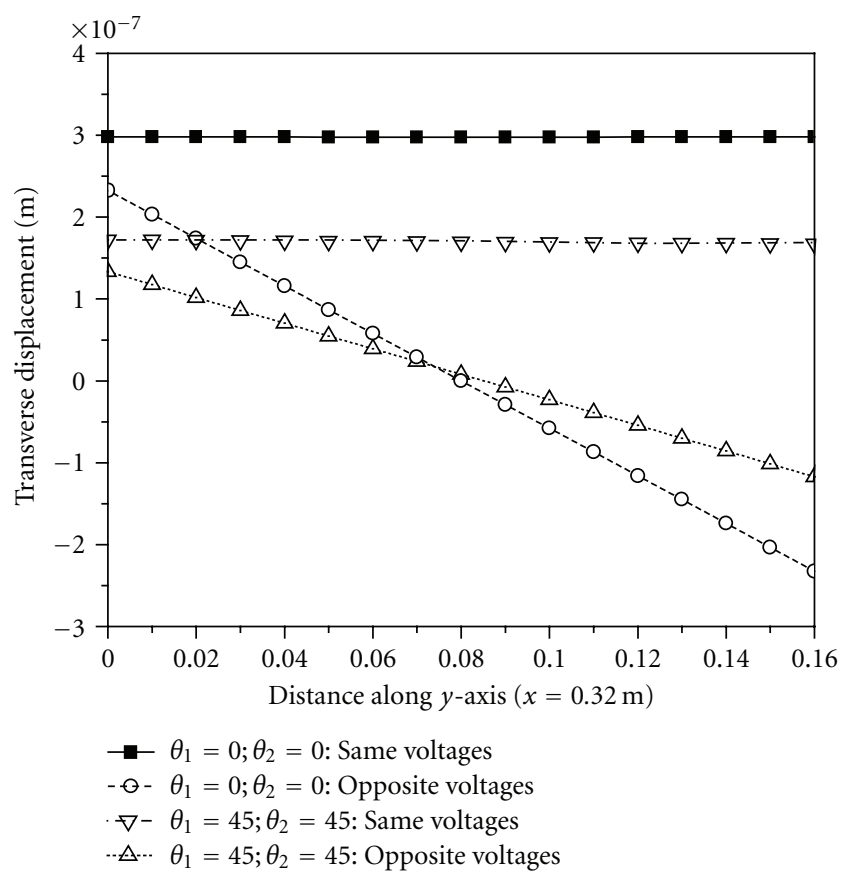

(b)

FIGURE 8: Clamped-free laminated plate with embedded SAFC actuators; passive element: [0/90/0/90/0/0/90/0/90/0]; active element: [0/90/SAFC/90/0]. 


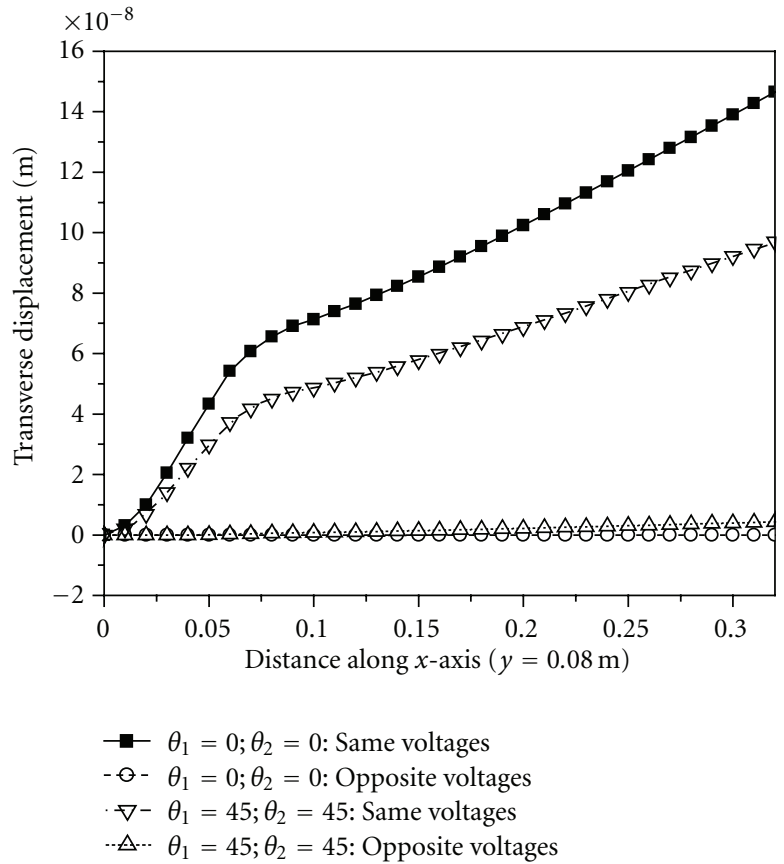

(a)

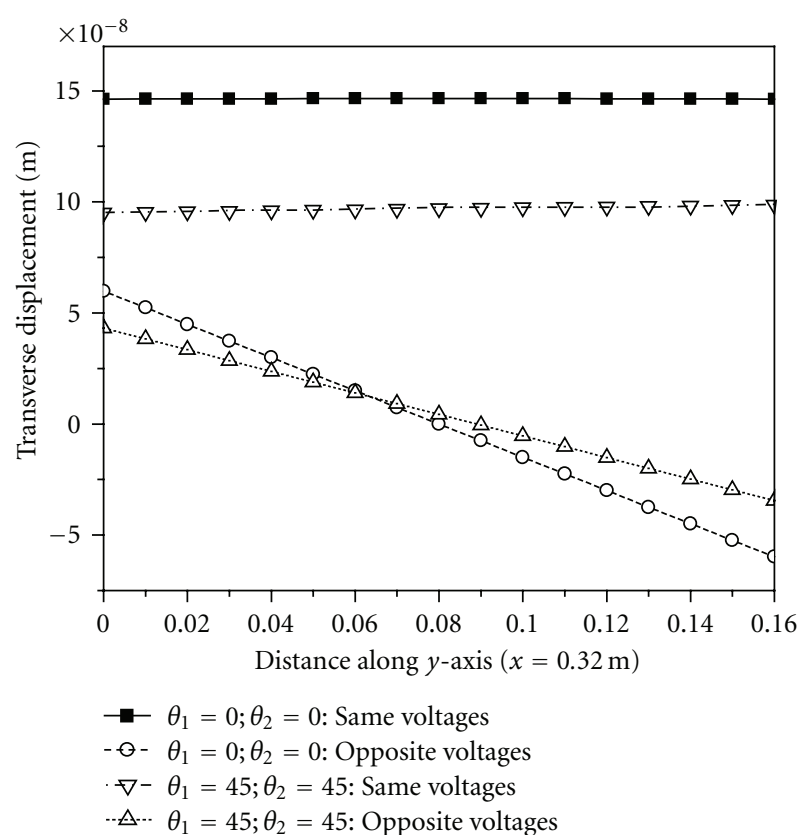

(b)

FIGURE 9: Clamped-free laminated plate with embedded SAFC actuators; passive element: [45/-45/45/-45/45/45/-45/45/-45/45]; active element: [45/-45/SAFC/-45/45].

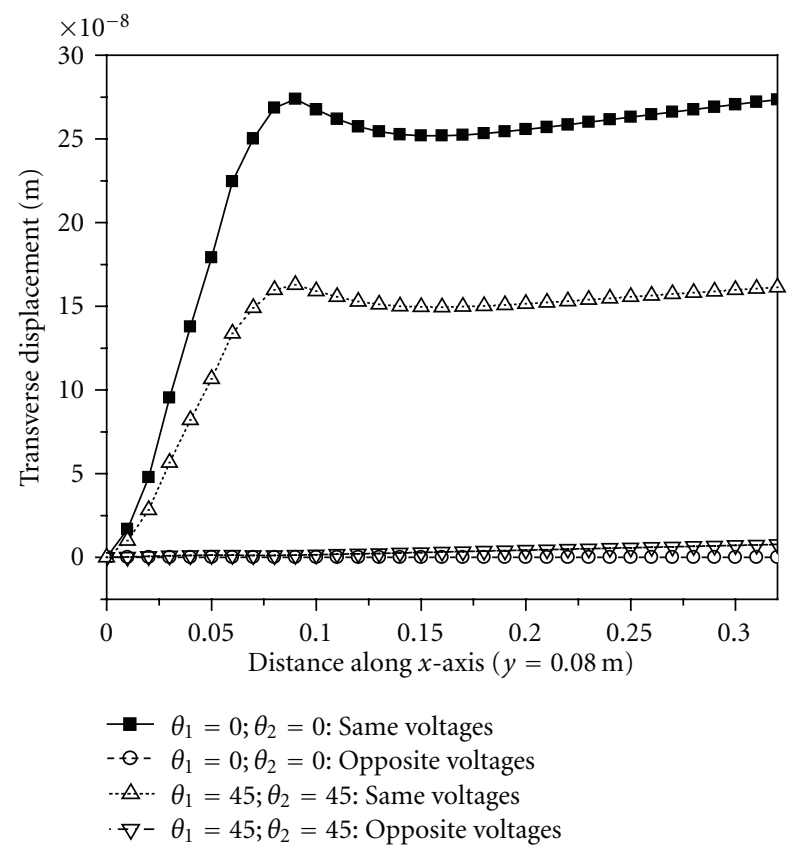

(a)

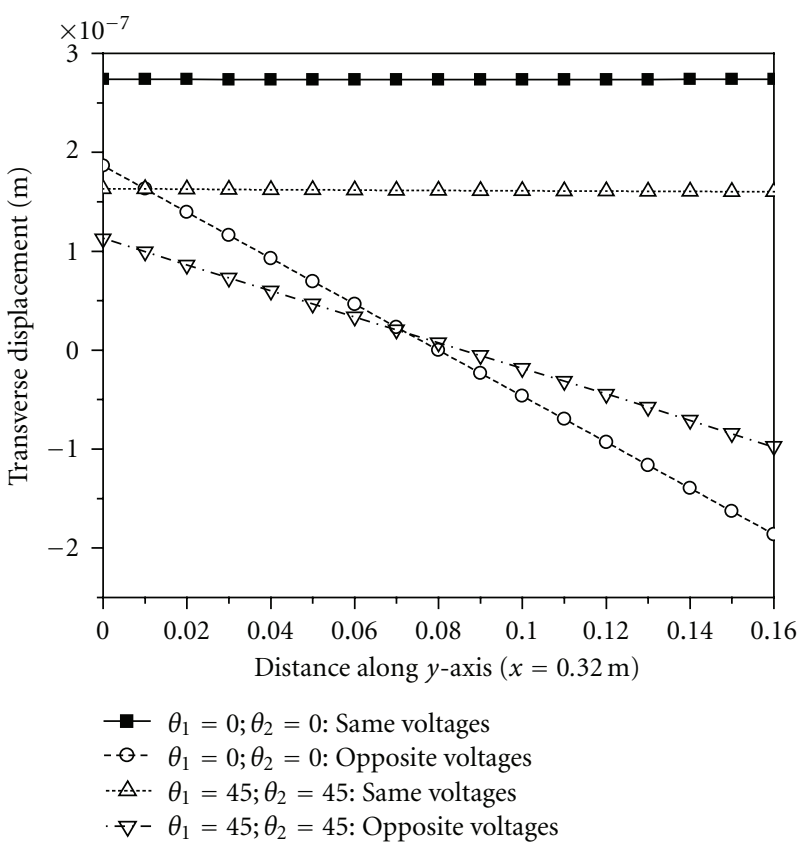

(b)

FIGURE 10: Clamped-free sandwich plate with embedded SAFC actuators passive element: [0/90/Foam/90/0]; active element: [0/90/Foam/SAFC/Foam/90/0]. 


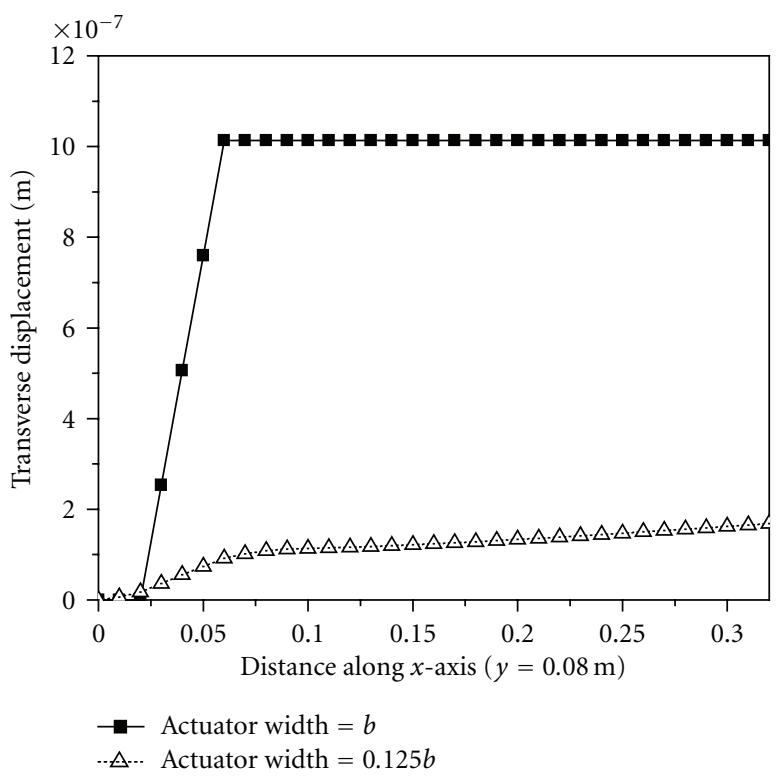

(a)

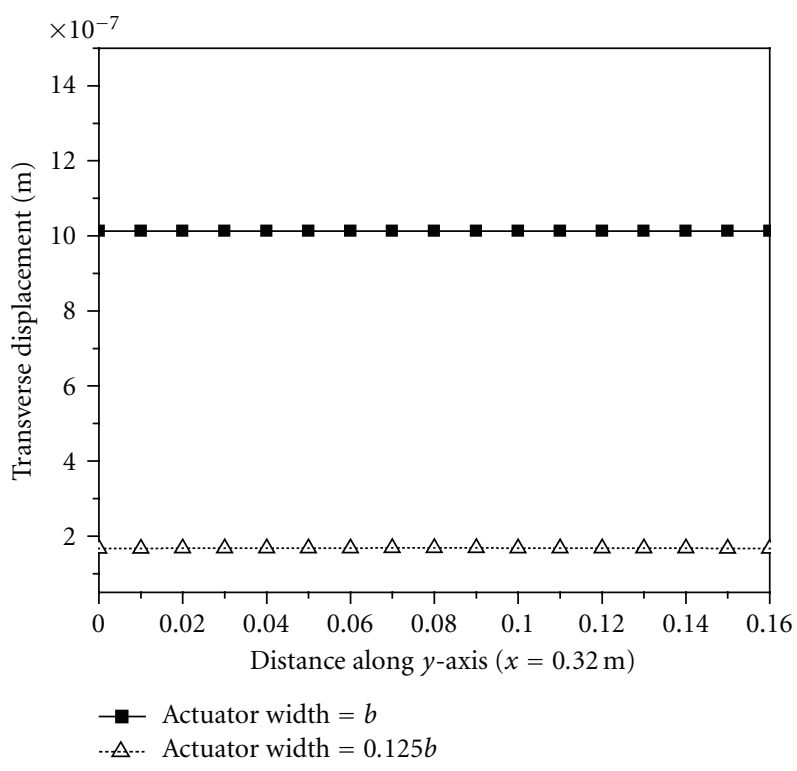

(b)

FIGURE 11: Clamped-free isotropic layered plate with embedded SAFC actuators; passive element: [AL/AL]; active element: [AL/SAFC/AL].

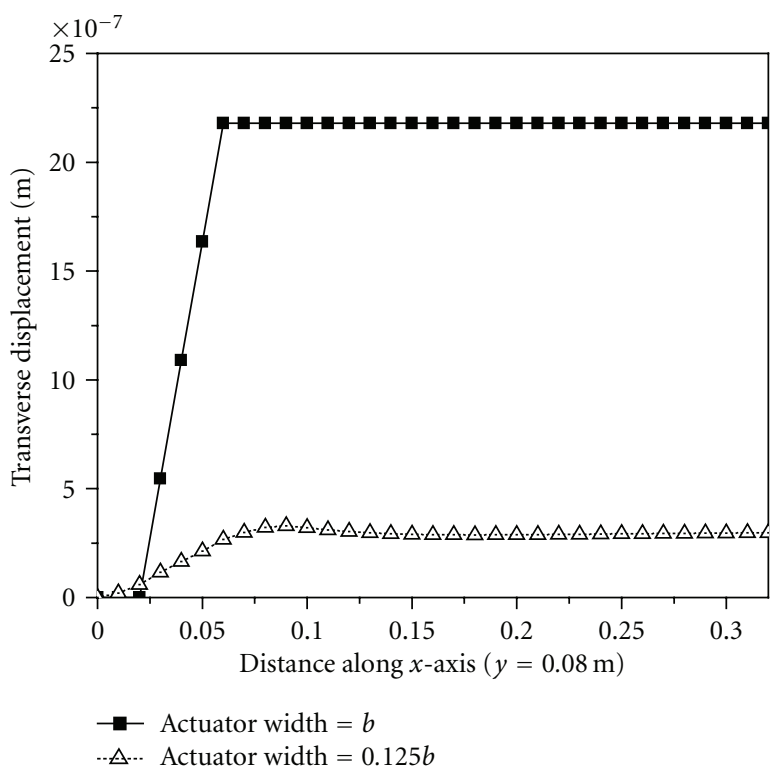

(a)

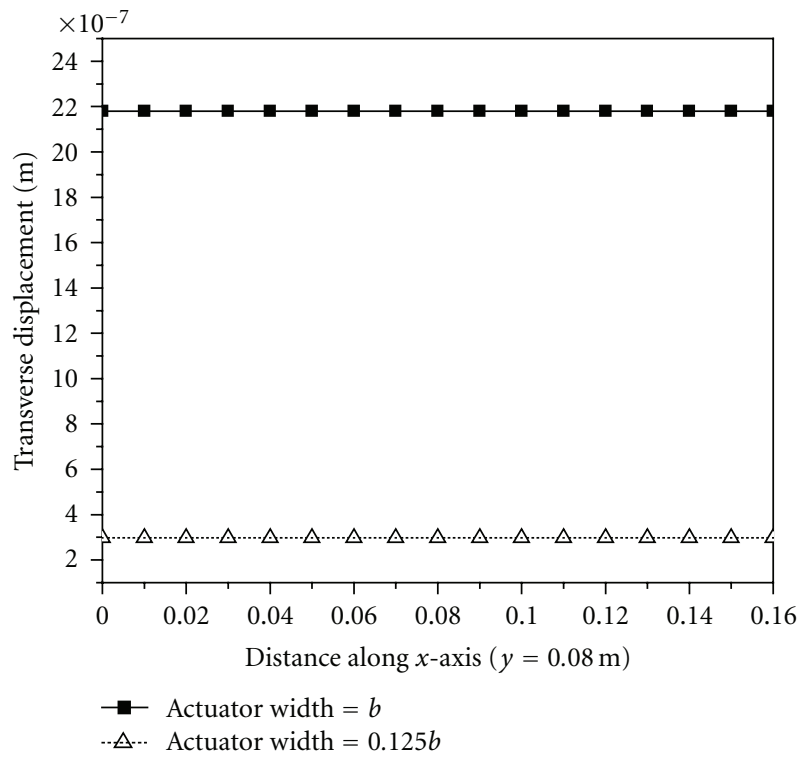

(b)

FIGURE 12: Clamped-free laminated plate with embedded SAFC actuators; passive element: [0/90/0/90/0/0/90/0/90/0]; active element: $[0 / 90 / \mathrm{SAFC} / 90 / 0]$.

an interesting closed loop damping performance for both bending and torsion vibrations.

\section{Conclusions}

A study has been made to evaluate the utilization of piezoelectric composite actuators for deflection and vibration con- trol applications. Two types of electro-mechanical actuations have been considered, and their modelling procedures are discussed. Finite element formulations are made to idealize the structural-piezoelectric interactions of these composite actuators and are implemented in a shear-flexible four-node plate element. A modal control approach is followed to study the active vibration control of laminated composite 


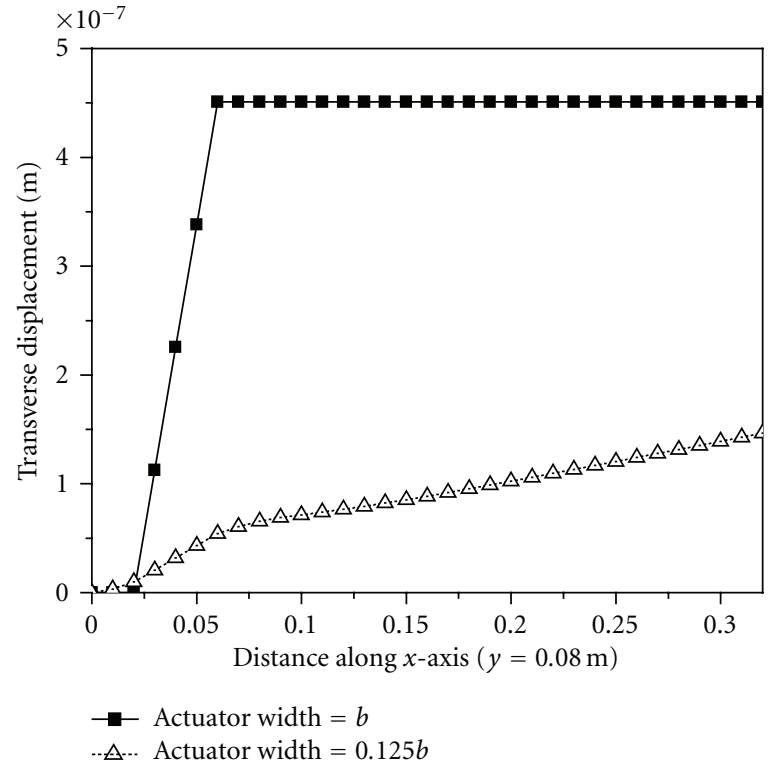

(a)

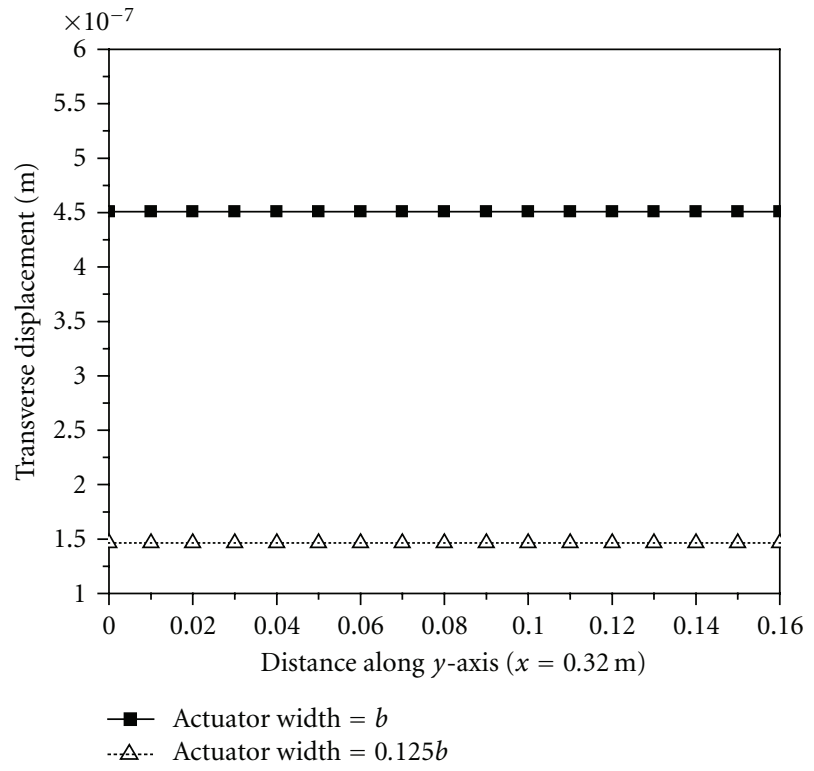

(b)

Figure 13: Clamped-free laminated plate with embedded SAFC actuators; passive element: [45/-45/45/-45/45/45/-45/45/-45/45]; active element: [45/-45/SAFC/-45/45].

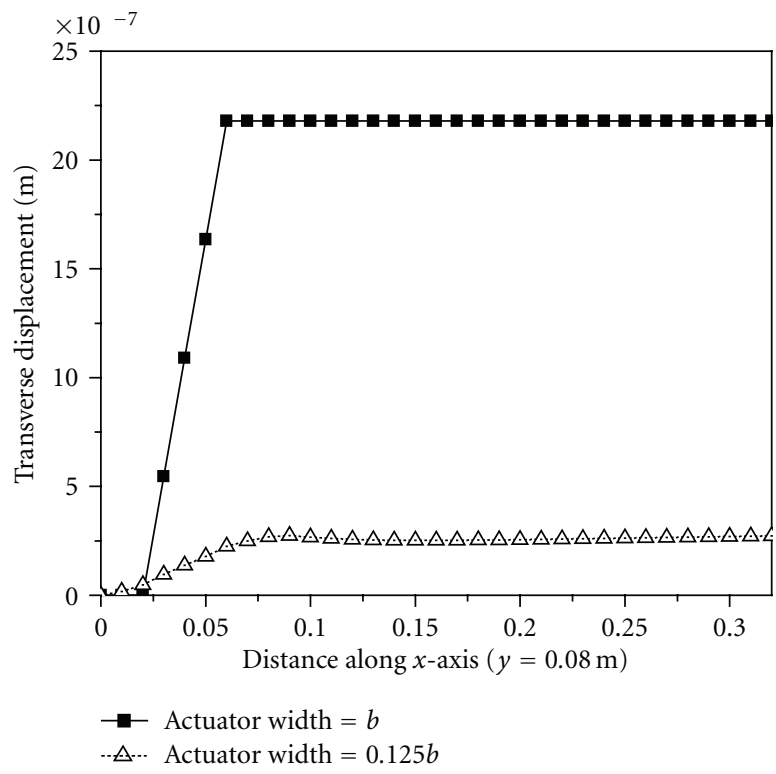

(a)

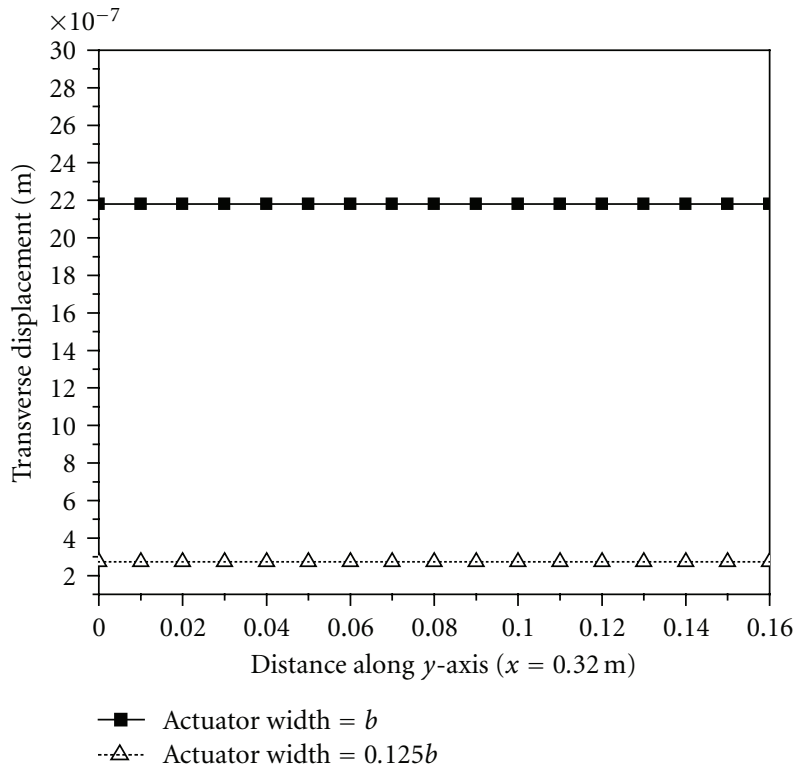

(b)

FIGURE 14: Clamped-free sandwich plate with embedded SAFC actuators passive element: [0/90/Foam/90/0]; active element: [0/90/Foam/SAFC/Foam/90/0].

plate structures. Influence of angle of actuation and actuator width has been examined for the newly proposed shear actuated fiber composite actuator (SAFC). Furthermore, its application to cross- and angle-ply laminated structures is analyzed, besides sandwich plate. Electromechanically developed extension-bending structural coupling by MFC appears to be promising in active control applications. However, the electromechanically induced shear-bending coupling by SAFC shows an interesting closed loop damping performance, which can be exploited to develop optimally actuated thin-walled laminated structures either independently or along with MFC actuators. This would provide 


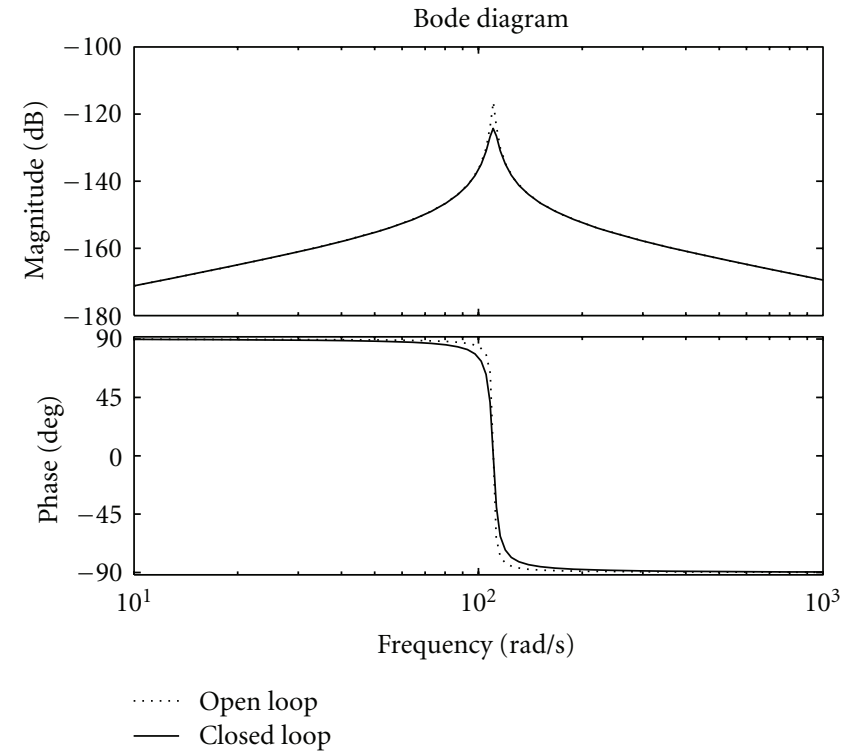

(a) Bode plot

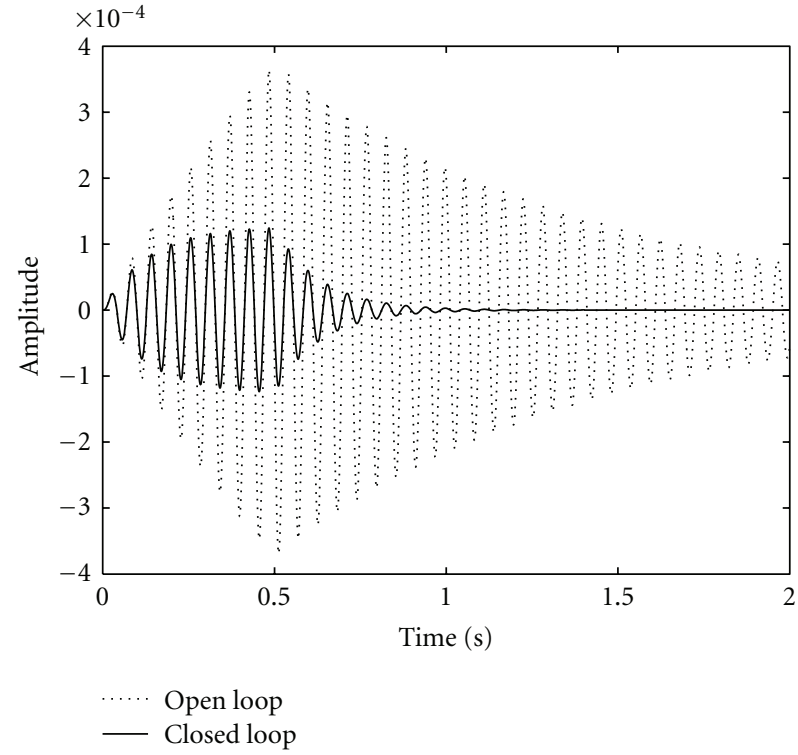

(b) Sine responses

Figure 15: Clamped-free laminated plate with surface-bonded MFC and -embedded SAFC actuators; passive element: [0/90/0/45/-45/ -45/45/0/90/0]; active element: [MFC/0/90/SAFC/90/0]; first mode control; SAFC active.

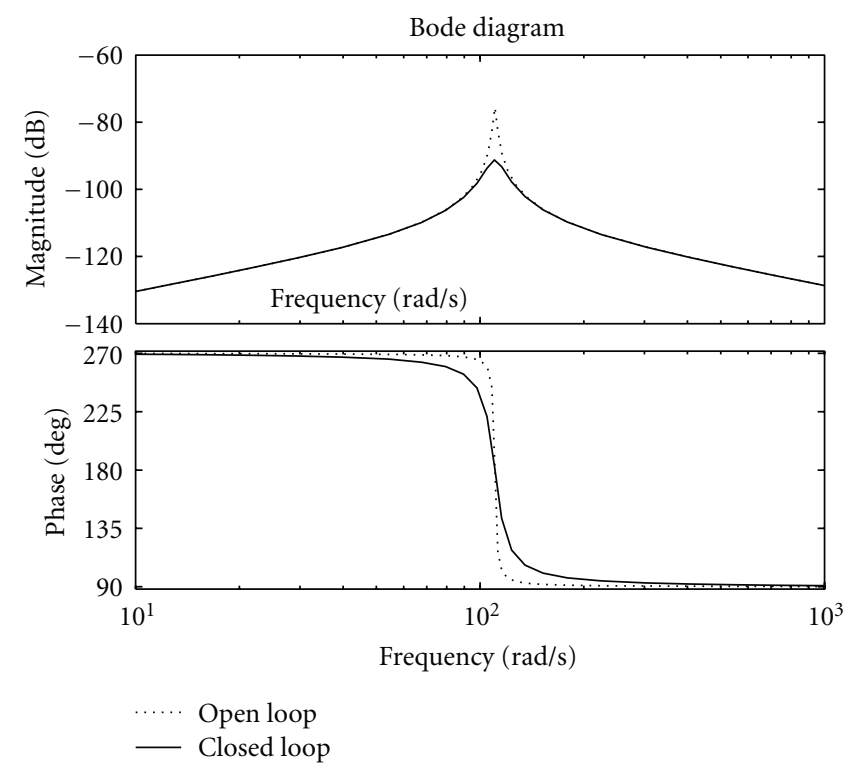

(a) Bode plot

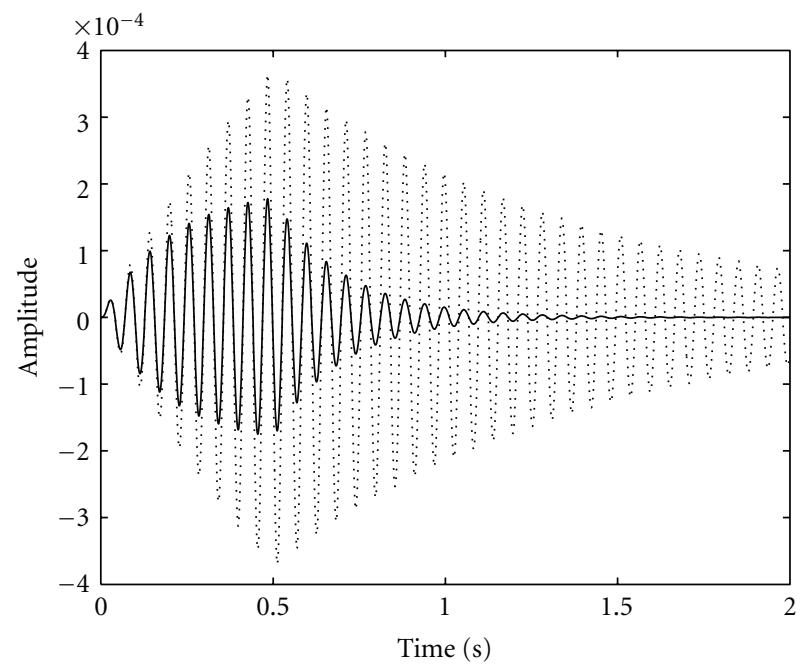

.... Open loop - Closed loop

Figure 16: Clamped-free laminated plate with surface-bonded MFC and -embedded SAFC actuators; passive element: [0/90/0/45/-45/-45/45/0/90/0]; active element: [MFC/0/90/SAFC/90/0]; first mode control; MFC active.

TABLE 2: Open and closed loop characteristics.

\begin{tabular}{|c|c|c|c|c|}
\hline \multirow{2}{*}{ Case } & \multicolumn{2}{|c|}{ Frequency (rad/sec) } & \multicolumn{2}{|c|}{ Damping (\%) } \\
\hline & Open & Closed & Open & Closed \\
\hline \multicolumn{5}{|c|}{ (a) First mode: bending } \\
\hline SAFC & 110.41 & 110.41 & 1.0 & 5.89 \\
\hline MFC & & & 1.0 & 3.51 \\
\hline \multicolumn{5}{|c|}{ (a) Second mode: torsion } \\
\hline SAFC & 228.64 & 228.64 & 0.5 & 1.48 \\
\hline MFC & & & 0.5 & 1.15 \\
\hline
\end{tabular}




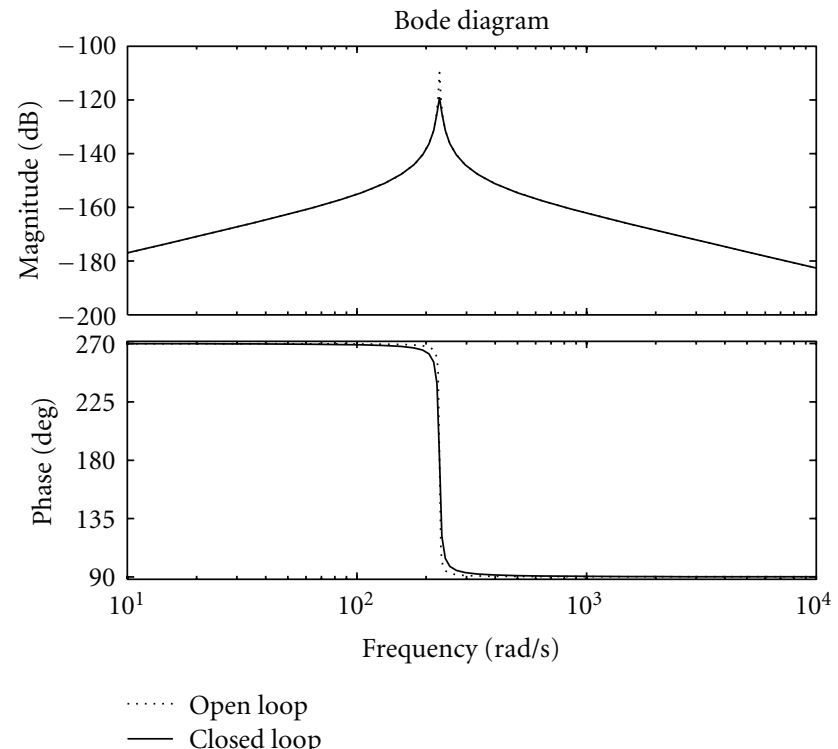

(a) Bode plot

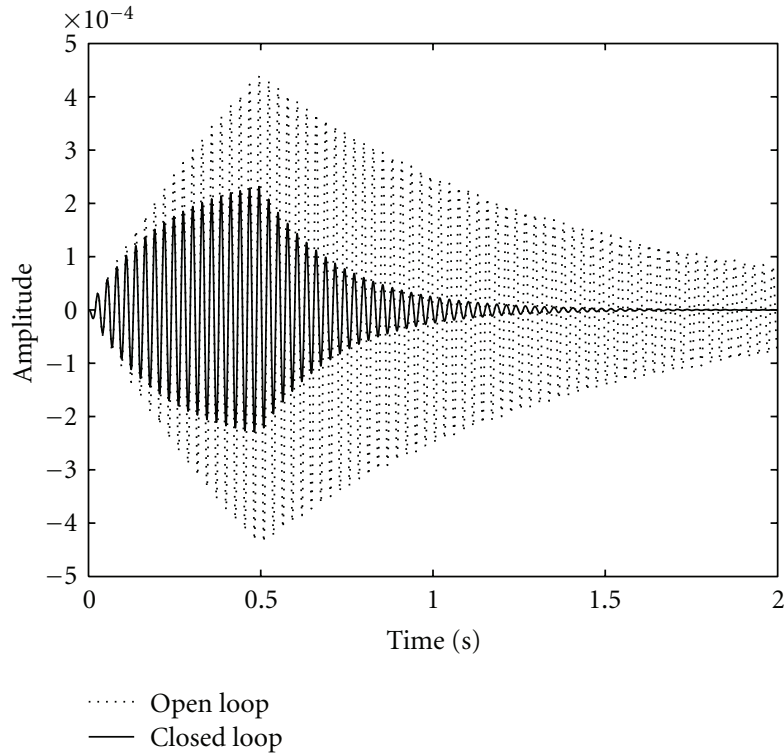

(b) Sine responses

Figure 17: Clamped-free laminated plate with surface-bonded MFC and -embedded SAFC actuators; passive element: [0/90/0/45/-45/-45/45/0/90/0]; active element: [MFC/0/90/SAFC/90/0]; second mode control; SAFC active.

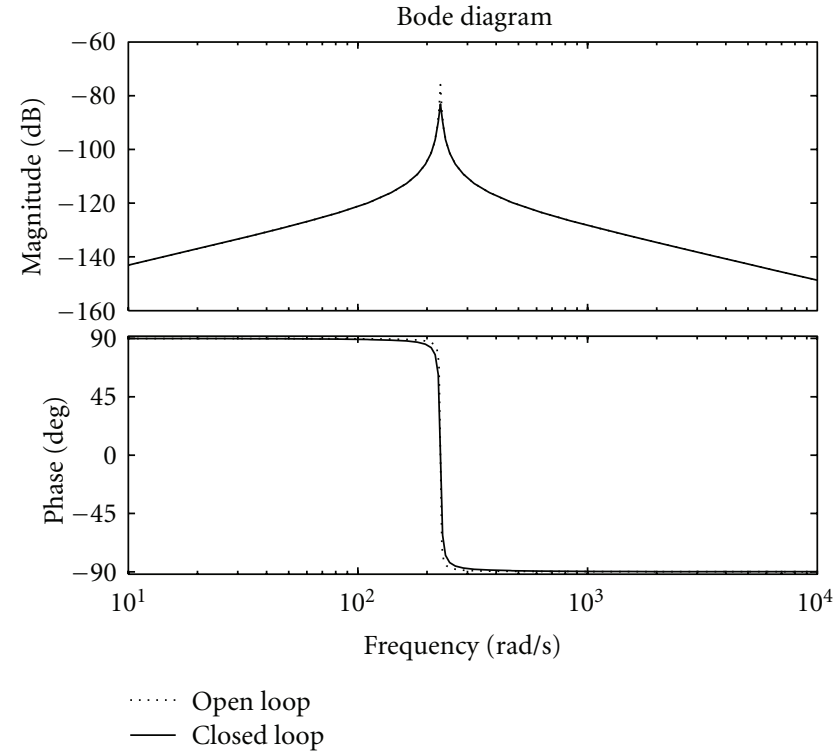

(a) Bode plot

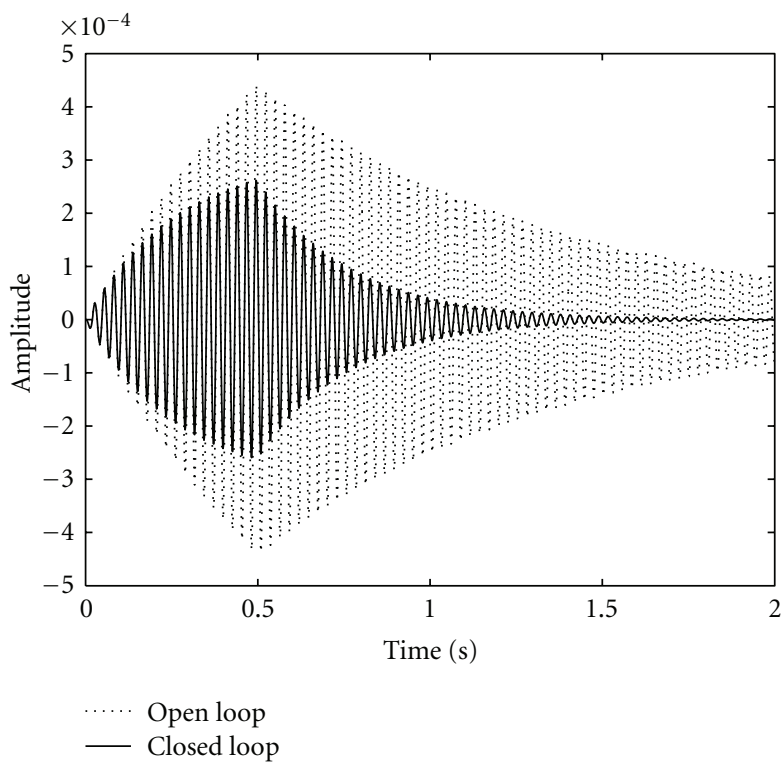

(b) Sine responses

Figure 18: Clamped-free laminated plate with surface-bonded MFC and -embedded SAFC actuators; passive element: [0/90/0/45/-45/-45/45/0/90/0]; active element: [MFC/0/90/SAFC/90/0]; second mode control, MFC active.

TABLE 3: Applied electric field.

\begin{tabular}{lcccc}
\hline \multirow{2}{*}{ Mode } & \multicolumn{2}{c}{ SAFC electric field $\left(\mathrm{V}_{\text {peak }} / \mathrm{mm}\right)$} & \multicolumn{2}{c}{ MFC electric field $\left(\mathrm{V}_{\text {peak }} / \mathrm{mm}\right)$} \\
& Patch 1 & Patch 2 & Patch 1 & 303 \\
(a) First mode: bending & 303 & 303 & 303 & 303 \\
(a) Second mode: torsion & 353 & 294 & 355 & 292 \\
\hline
\end{tabular}


a greater flexibility to design damage tolerant smart structures to handle the unsteady aerodynamic loads.

\section{Notations}

$\begin{array}{ll}\sigma: & \text { Normal stress }\left(\mathrm{N} / \mathrm{m}^{2}\right) \\ \varepsilon: & \text { Normal strain } \\ \tau: & \text { Shear stress }\left(\mathrm{N} / \mathrm{m}^{2}\right) \\ \gamma: & \text { Shear strain } \\ \mathrm{D}: & \text { Dielectric displacement }\left(\mathrm{C} / \mathrm{m}^{2}\right) \\ E: & \text { Electric field }(\mathrm{v} / \mathrm{m}) \\ c: & \text { Elastic constants }\left(\mathrm{N} / \mathrm{m}^{2}\right) \\ e: & \text { Piezoelectric stress constant }\left(\mathrm{C} / \mathrm{m}^{2}\right) \\ d: & \text { Piezoelectric strain constant }(\mathrm{C} / \mathrm{N}) \\ \in: & \text { Dielectric permittivity }(\mathrm{F} / \mathrm{m}) \\ \vec{P}: & \text { Polarization vector } \\ f_{b}, f_{s}: & \text { Body force, surface traction, respectively } \\ u, \phi: & \text { Mechanical displacement, electric potential, } \\ & \text { respectively } \\ U: & \text { Internal energy } \\ q, \rho: & \text { Surface charge }(\mathrm{C}), \text { density }\left(\mathrm{kg} / \mathrm{m}^{3}\right) \\ \delta: & \text { Variational operator } \\ h_{k}: & \text { Thickness of the } k \text { th lamina } \\ \bar{Q}_{i j}: & \text { Transformed stiffness coefficients } \\ x, y, z: & \text { Rectangular co-ordinate system } \\ \mathrm{SCF}: & \text { Shear correction factor } \\ \mathrm{IDE}: & \text { Interdigitated electrode } \\ a, s: & \text { Actuator, sensor, respectively } \\ d v, d s: & \text { Volume, area, respectively } \\ w_{e}: & \text { Finger electrode width } \\ A, B, D: & \text { Composite stiffness coefficients } \\ \Psi: & \text { Modal coordinate } \\ \chi: & \text { State vector } \\ A_{i}, B_{i}: & \text { ith mode state space matrices } \\ \Delta t: & \text { Sampling time } \\ & \end{array}$

\section{Acknowledgment}

The first author was a JSPS Fellow (2006-2007) and the funding received to pursue this research has been greatly acknowledged.

\section{References}

[1] N. W. Hagood and A. A. Bent, "Development of piezoelectric fiber composites for structural actuation," in Proceedings of the 34th AIAA/ASME Structures, Structural Dynamics, and Materials Conference, pp. 3625-3638, La Jolla, Calif, USA, April 1993.

[2] A. A. Bent, "Active fiber composite material systems for structural control applications," in Proceedings of the 6th International Symposium on Smart Structures and Materials, Proceedings of SPIE, Newport Beach, Calif, USA, March 1999.

[3] W. K. Wilkie et al., "Low-Cost piezocomposite actuator for structural control applications," in Proceedings of the 7th International Symposium on Smart Structures and Materials, Proceedings of SPIE, Newport Beach, Calif, USA, March 2000.

[4] M. S. Azzouz, C. Mei, J. S. Bevan, and R. J. Jong, "Finite element modeling of MFC/AFC actuators and performance of
MFC," Journal of Intelligent Material Systems and Structures, vol. 12, no. 9, pp. 601-612, 2001.

[5] E. J. Ruggiero, G. T. Bonnema, and D. J. Inman, "Application of SISO and MIMO modal analysis techniques on a membrane mirror satellite," in Proceedings of the ASME International Mechanical Engineering Congress, pp. 63-69, Washington, DC, USA, November 2003, IMECE2003-41710.

[6] H. A. Sodano, G. Park, and D. J. Inman, "An investigation into the performance of macro-fiber composites for sensing and structural vibration applications," Mechanical Systems and Signal Processing, vol. 18, no. 3, pp. 683-697, 2004.

[7] J. S. Park and J. H. Kim, "Analytical development of single crystal Macro Fiber Composite actuators for active twist rotor blades," Smart Materials and Structures, vol. 14, no. 4, pp. 745$753,2005$.

[8] A. Benjeddou, M. A. Trindade, and R. Ohayon, "New shear actuated smart structure beam finite element," AIAA Journal, vol. 37, no. 2-3, pp. 378-383, 1999.

[9] X. D. Zhang and C. T. Sun, "Analysis of a sandwich plate containing a piezoelectric core," Smart Materials and Structures, vol. 8, no. 1, pp. 31-40, 1999.

[10] O. J. Aldraihem and A. A. Khdeir, "Smart beams with extension and thickness-shear piezoelectric actuators," Smart Materials and Structures, vol. 9, no. 1, pp. 1-9, 2000.

[11] S. S. Vel and R. C. Batra, "Exact solution for rectangular sandwich plates with embedded piezoelectric shear actuators," AIAA Journal, vol. 39, no. 7, pp. 1363-1373, 2001.

[12] S. Raja, G. Prathap, and P. K. Sinha, "Active vibration control of composite sandwich beams with piezoelectric extensionbending and shear actuators," Smart Materials and Structures, vol. 11, no. 1, pp. 63-71, 2002.

[13] S. Raja, S. Rajappa, and R. Sreedeep, "Active vibration control of shear actuated piezoelectric sandwich beam-experiment," in Proceedings of the 3rd International Conference on Theoretical, Applied, Computational and Experimental Mechanics (ICTACEM '04), IIT-Kharagpur, Kharagpur, India, December 2004.

[14] B. P. Baillargeon and S. S. Vel, "Active vibration suppression of sandwich beams using piezoelectric shear actuators: experiments and numerical simulations," Journal of Intelligent Material Systems and Structures, vol. 16, no. 6, pp. 517-530, 2005.

[15] S. Raja and I. Tadashige, "Concept and electro-elastic modelling of shear actuated fiber composite using micromechanics approach," Journal of Intelligent Material Systems and Structures, vol. 19, no. 10, pp. 1173-1184, 2008.

[16] R. M. Jones, Mechanics of Composite Materials, Taylor \& Francis, London, UK, 2nd edition, 1999. 

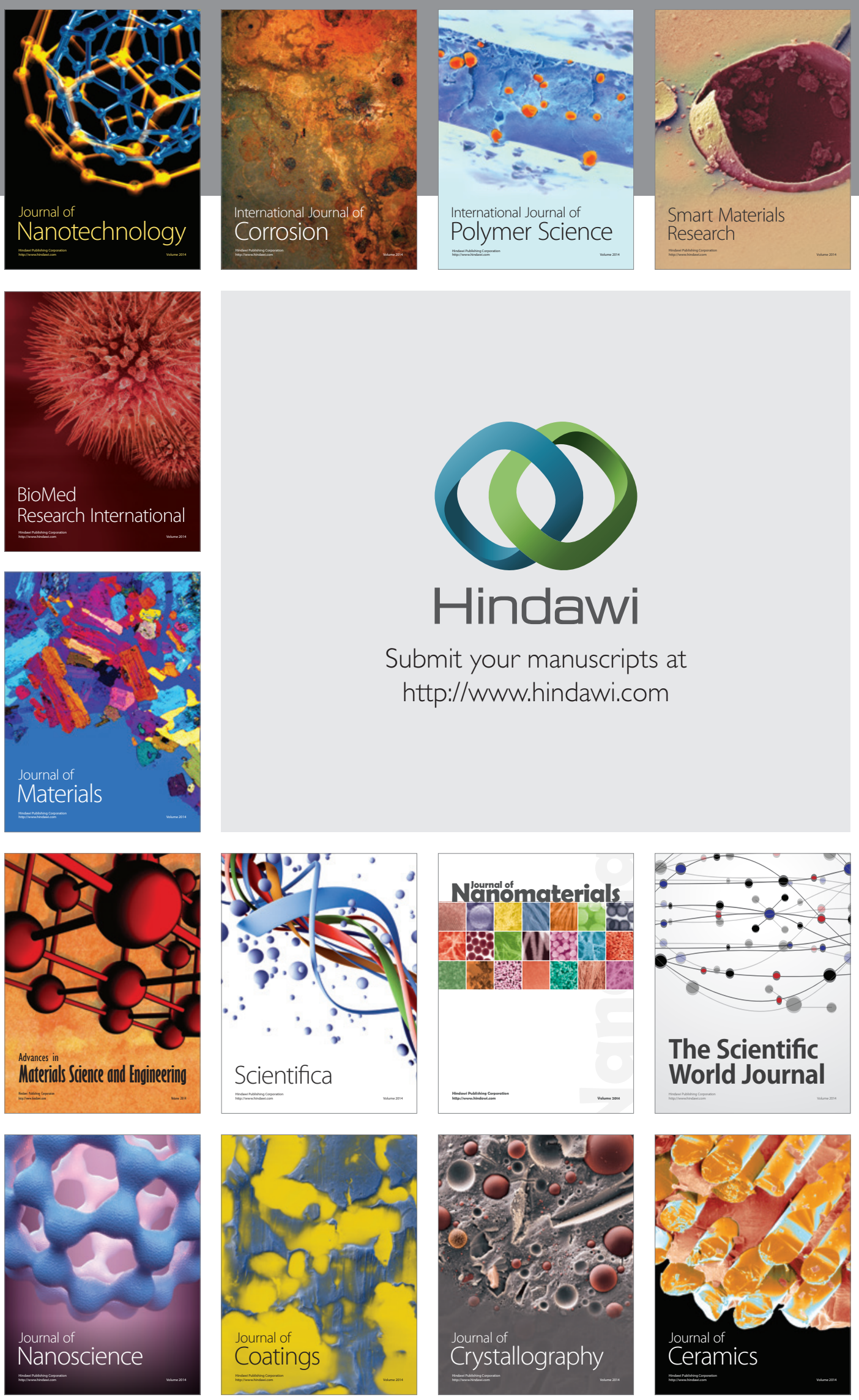

The Scientific World Journal

Submit your manuscripts at

http://www.hindawi.com

\section{World Journal}

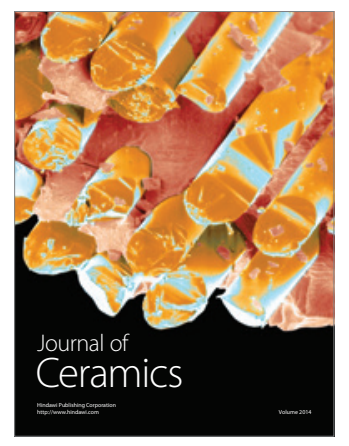

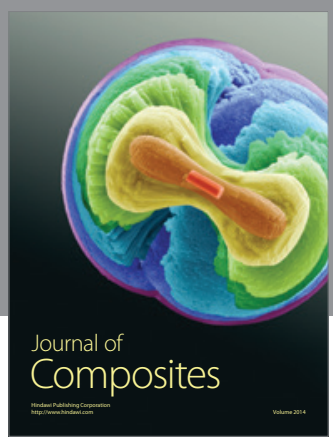
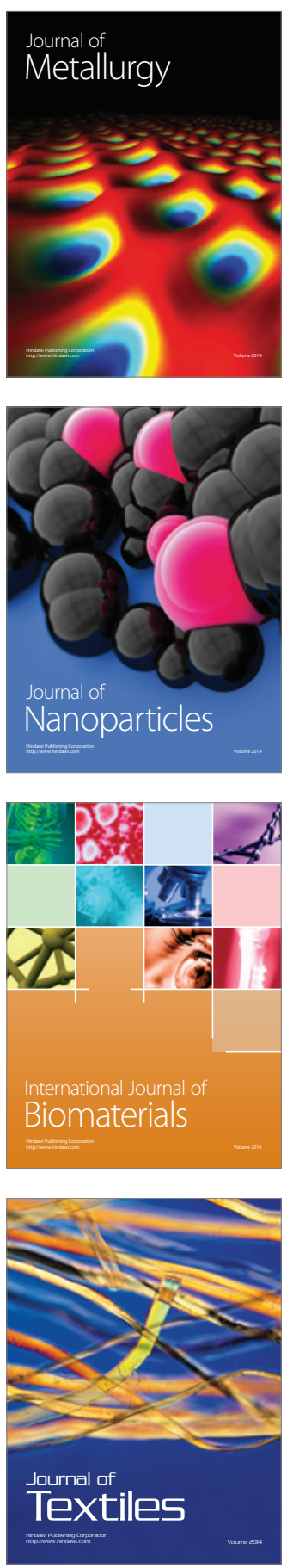